\title{
The impact of climate change on flow conditions and wetland ecosystems in the Lower Biebrza River (Poland)
}

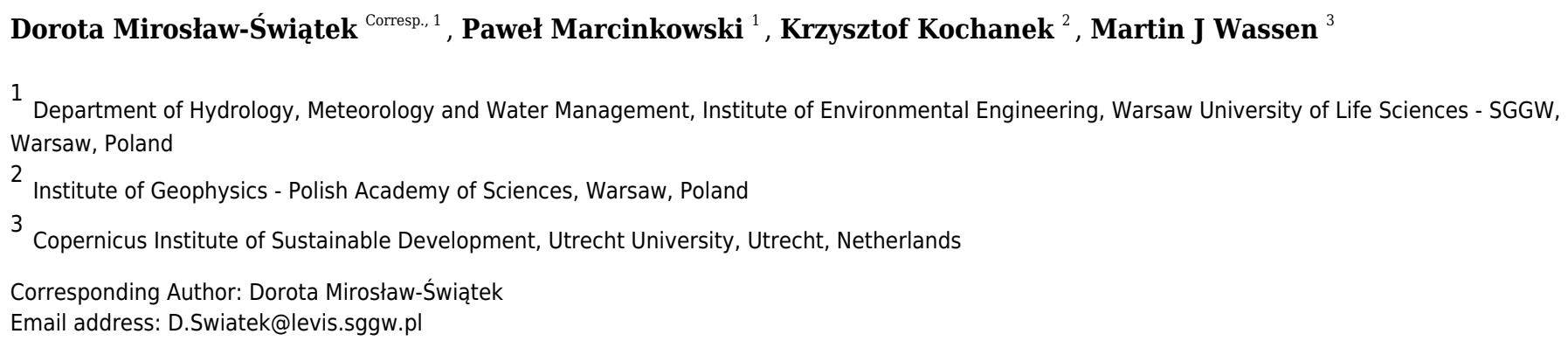

Water plays a key role in the functioning of wetlands and a shortage or contamination of it leads to changes in habitat conditions and degradation of ecosystems. This paper scrutinizes the impact of climate change on the hydrological characteristics of floods (maximum flow, duration, volume) in the River Biebrza wetlands (North-East Poland). We analysed the trends in duration and volume of flood and maximum discharges in the historical period 1970-2000 and predicted these for the future periods 2020-2050 and 2070-2100, respectively. Next we assessed the impact on the wetland ecosystems. The basis of our assessments consists of statistical analyses of hydrographs and calculations by the Soil and Water Assessment Tool (SWAT) hydrological model and considering nine bias-corrected climate models. The results indicate that both volume and duration of winter floods will keep increasing continuously under Representative Concentration Pathways (RCP) 4.5 and 8.5. The reduction in peak annual floods is expected to decline slightly in both scenarios. On the other hand, the analysis of trends in mean and standard deviation revealed negligible tendencies in the datasets for summer and winter hydrological seasons within the three time frames analysed (1970-2000; 2020-2050; 2070-2100). We foresee several future implications for the floodplain ecosystems. Shifts in transversal ecosystem zonation parallel to the river will likely take place with more highly productive flood tolerant vegetation types. Nutrient availability and algal blooms during spring inundations will likely increase. Slowdown of organic matter turnover later in summer will lead to a higher peat accumulation rate. Logistical problems with summer mowing and removal of bushes in winter may enhance shrub encroachment. 
1 The impact of climate change on flow conditions and wetland

2 ecosystems in the Lower Biebrza River (Poland)

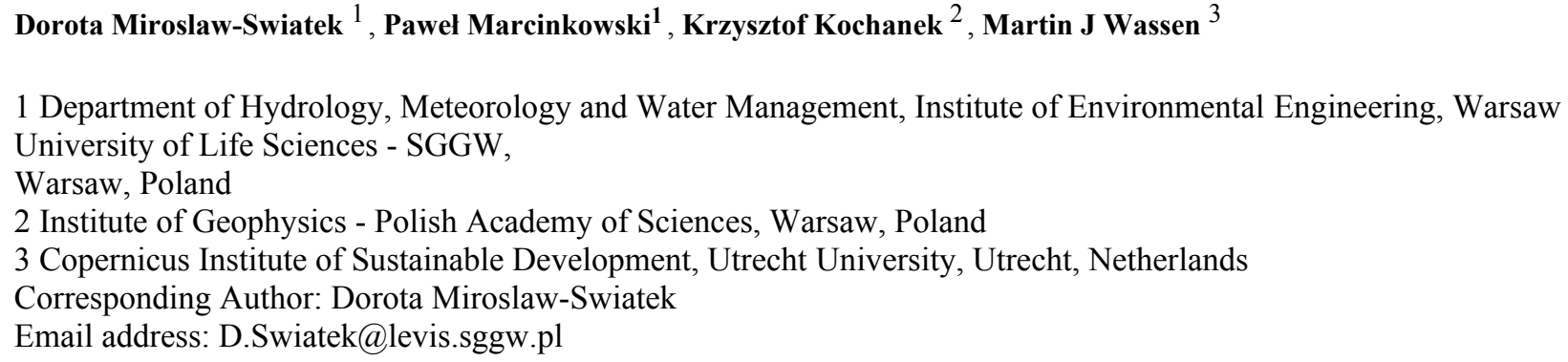

\begin{abstract}
Water plays a key role in the functioning of wetlands and a shortage or contamination of it leads to changes in habitat conditions and degradation of ecosystems. This paper scrutinizes the impact of climate change on the hydrological characteristics of floods (maximum flow, duration, volume) in the River Biebrza wetlands (North-East Poland). We analysed the trends in duration and volume of flood and maximum discharges in the historical period 1970-2000 and predicted these for the future periods 2020-2050 and 2070-2100, respectively. Next we assessed the impact on the wetland ecosystems. The basis of our assessments consists of statistical analyses of hydrographs and calculations by the Soil and Water Assessment Tool (SWAT) hydrological model and considering nine bias-corrected climate models. The results indicate that both volume and duration of winter floods will keep increasing continuously under Representative Concentration Pathways (RCP) 4.5 and 8.5. The reduction in peak annual floods is expected to decline slightly in both scenarios. On the other hand, the analysis of trends in mean and standard deviation revealed negligible tendencies in the datasets for summer and winter hydrological seasons within the three time frames analysed (1970-2000; 2020-2050; 2070-2100). We foresee several future implications for the floodplain ecosystems. Shifts in transversal ecosystem zonation parallel to the river will likely take place with more highly productive flood tolerant vegetation types. Nutrient availability and algal blooms during spring inundations will likely increase. Slowdown of organic matter turnover later in summer will lead to a higher peat accumulation rate. Logistical problems with summer mowing and removal of bushes in winter may enhance shrub encroachment. Introduction
\end{abstract}

Wetlands, due to their functions in biodiversity and landscape preservation, formation of habitats for many endemic plant and animal species, and also in reducing the outflow of groundwater into rivers thus providing protection from erosion and floods, retaining groundwater and surface water, water purification and accumulation of organic matter, are among the most valuable natural systems on Earth and belong to the most complex ecosystems (Costanza et al., 1997, 2014). Water plays a key role in the functioning of wetlands, and a shortage or contamination of it leads to changes in habitat conditions and the degradation of ecosystems. An exploitative approach to the management of natural resources, which concentrated on using these ecosystems for production purposes only (downgraded by drainage in order to convert it into agricultural land or by wasteful exploitation of peat), resulted in many wetlands becoming endangered and losing their original functions (Joosten and Clarke, 2004). The roots of the wetlands' natural 
dysfunction may stem not only from the evident anthropo-pressure, but also from climate change, which is a serious threat potentially leading to transformation of hydrological conditions (Dorau et al., 2015).

The activities aimed at restoring the selected functions of transformed wetland ecosystems or maintaining a good condition and ecological balance of properly functioning ecosystems are nowadays the issues at stake related to the environmental management process. Therefore, it is extremely important to consider the interplay of pressures resulting from human activities, climate change and ecological dependencies (Mitsch, 2014). Quantifying these elements, forecasting their variability in the future, as well as taking into account their impact on ecosystems still poses a problem. Although the impact of climate change on wetland hydrology has been studied this is mostly done on a global, continental or national scale (Hoegh-Guldberg \& Bruno (2010); Witte et al. (2012); Finlayson (2013); Thompson et al. (2019)) and not targeted at specific wetland areas of interest. Therefore it remains challenging to assess the impact of climate change on wetland hydrological characteristics and on the occurrence and functioning of ecosystems in wetlands of special interest.

The River Biebrza Valley, where the river has retained its natural lowland character, is part of the largest peat complex in Central Europe. It is one of the most valuable and demanding (in terms of marsh management) ecosystems in Europe. The Biebrza fens and marshes function as a reference area for activities aimed at restoration of wetlands for many transformed river valleys in Europe (Bootsma et al., 2000; Wassen et al., 2006). The regular occurrence of spring floods in the lower Biebrza basin (LBB) is the main factor conditioning the development and functioning of diverse wetland ecosystems. The valley inundation occurs almost every year and lasts from several weeks to several months. The origins of these inundations are twofold: spring thaws and melting of snow and high precipitation (Kicinski and Byczkowski, 1983). Berezowski et al. (2018) analysed long-term (1960-2012) changes in meteorology, hydrology, soil and vegetation, and also conservation history and found significant trends indicating climate change: increases in temperature and evapotranspiration and earlier start of spring floods. They also identified (19702000) a shift towards drier vegetation types, but also found that local restoration measures such as blocking drainage via ditches, not clearing aquatic vegetation, bush removal and mowing that were implemented have mitigated climate change effects and have led to increases in soil moisture and wetter vegetation types in some areas.

The River Biebrza's abundant spring floods determine the development of wetland plants and shape rich feeding grounds, especially for wetland birds which make the Biebrza Valley the most valuable bird refuge in Europe as a nesting and feeding area and during migration (Maciorowski et al., 2014). The occurrence and zonation of wetland ecosystems with a fluviogenic type of supply is associated with the dynamics of floods, which provide a diversity of habitats depending on the duration and extent of the flood events (Chormański et al., 2009).

To quantify the impacts of climate change on regional hydrological regimes, the outcomes of climate models coupled with hydrologic models are commonly used (Arnell and Gosling, 2013). One of the most popular hydrological models used in the assessment of climate change impact on different sectors, including environment, is Soil and Water Assessment Tool (SWAT) model. 
87 It has been applied in numerous studies investigating climate change impact on wetlands 88 ecosystems hydrology and well-being (Zhang et al., 2011; Kundzewicz et al., 2017, O'Keeffe et 89 al., 2019).

90 The issues related to the quantitative assessment of climatic pressures and their role in the

91

92

93

94

95

96

97

98

99

100

101

102

103

104

105

106

107

108

109

110

111

112

113

114

115

116

117

118

119

120

121

122

123

124

125 management of ecosystems in the Biebrza Valley have not been widely discussed in the literature. So far, the main focus has been on the pressure related to agricultural use of these areas (e.g. Swiatek et al., 2008). Grygoruk et al. (2014) analysed the changes in average monthly precipitation in this area in a simplified way based on historical observations and ten separate forecasts of climate changes in the Biebrza Valley for 2070-2100 with different combinations of General Circulation Models (GCM) and Regional Climate Models (RCM). They describe the potential effects of the most negative scenario of climate change - the possibility of winter drought (no snow accumulation, low rainfall) and hot summers with high episodic rainfall separated by weeks of droughts. The use of these forecasted climate changes by the Biebrza National Park to implement an adaptive management model was proposed in Grygoruk and Rannow (2017).

The multiannual tendencies of climatic changes (e.g. mean annual precipitation, temperature and snow cover) and variability of hydrologic characteristics (annual maxima in winter seasons and water discharge and stage in summer seasons) in the Biebrza River basin in 1966-2003 were analysed using the Mann-Kendall test by Maksymiuk et al. (2008).

In riparian wetlands the extends and duration of floods keep floodplain ecosystems in appropriate hydrological and geochemical conditions (Chormański et al., 2009, 2011; Swiatek et al., 2008). We will show that these hydrological indicators in the Lower Biebrza basin are closely related to the characteristics of floods observed at the Osowiec water gauge . The aim of the current paper is to assess the impact of climate change on (1) the hydrological characteristics of floods (duration, volume, maximum flow) and on (2) specific wetland ecosystems. For this we carried out statistical analyses of the hydrographs derived from the SWAT hydrological model for the historical period 1970-2000 and future time horizons 2020-2050 (near future (NF)) and 2070-2100 (far future (FF)), considering nine bias-corrected climate models at the Osowiec water gauge. Next, we qualitatively assessed expected changes in ecosystems resulting from the estimated hydrological and subsequent other environmental changes.

\section{Materials and Methods}

\section{Study area}

The study was carried out in the northern part of the Lower Basin of the River Biebrza Valley, considered a well preserved, natural floodplain ecosystem representing main ecological features of such systems in temperate European lowlands (Fig. 1). This area (6300 ha) is located in North-Eastern Poland and is characterized by a broad land depression filled with sand, on which peat soils were developed in the Holocene. The valley was shaped in the late Pleistocene by 
126 fluvio-glacial waters of the Vistulian Glaciation. The floodplain is covered by a mosaic of 127 marshy vegetation ranging from sedge, sedgemoss and reed communities to willow shrubs, black 128 alder forest, swampy birch and peat coniferous forest, and this area is among the most valuable 129 wetlands globally (Wassen et al., 2006). The valuable ecosystems here are also represented by 130 the large areas of open semi-meadows with near-natural vegetation, which are the result of 131 agriculturally managed as extensively used meadows of a seasonal mowing regime. Among the 132 dominant plant communities the four following alliances are of special interest in the floodplain:

133 Caricetum appropinquatae, Caricetum gracilis, Glycerietum maximae and Phragmitetum 134 communis (Fig 1.). These alliances are typical for temperate European floodplains that developed 135 in peat-filled valleys and which represent unique biodiversity (Budka et al., 2019). The 136 elevations in the study area vary from 103 up to $118.5 \mathrm{~m}$ a.s.l. (Mirosław-Świątek et al., 2016). 137 The average annual air temperature is $6.6^{\circ} \mathrm{C}$ (Banaszuk, 2004) and the average annual sum of 138 precipitation is as high as $560 \mathrm{~mm}$ (Kossowska-Cezak et al., 1984). The Lower Basin is part of the most valuable bird habitat as a site of nesting, foraging and migration (Polakowski et al., 140 2014) and also as an area protecting valuable and rare species of birds residing in the wetlands 141 (Maciorowski et al., 2014). The healthy floodplain ecosystem functioning in the Lower Biebrza 142 is connected with the river Biebrza flooding regularly every year for at least several weeks or 143 months (Kiciński and Byczkowski, 1983). Grygoruk et al., (2013), basing upon the results of 144 national hydrological survey, noticed that when the discharge exceeds $25 \mathrm{~m}^{3} / \mathrm{s}$ at the Osowiec 145 gauge, we can expect the floodplain to be flooded. In such a case the water depth in the 146 floodplains may reach $1.5 \mathrm{~m}$ (Mirosław-Świątek, 2017). Wetlands of Lower Biebrza basin 147 depend on the interactions between seasonal flooding, groundwater discharge and rain 148 (snowmelt) water accumulation (Berezowski et al., 2019; Chormański et al., 2011). But in the 149 northern part of the basin, where our study area is located, the main mechanism of flooding is the 150 river flood wave. Its hydrological characteristics are observed at the Osowiec gauge (Fig. 1) 151 (Okruszko, 2005).

\section{Soil and Water Assessment Tool (SWAT) model}

153 The SWAT model is a process-based, continuous-time model which simulates the movement of 154 water, sediment, and nutrients on a catchment scale (Arnold et al., 1998). It is suitable for 155 investigating the interaction between climate, land use, and water quantity. The SWAT model 156 enables simulation of long-term impacts of climate changes on water, sediment, and nutrient 157 loads in catchments with varied topography, land use, soils and management conditions. The 158 catchment area is divided into sub-basins and further into Hydrologic Response Units (HRU), 159 which are the smallest spatially distinguishable units. Water balance, sediment and nutrient loads are calculated for each HRU. Runoff is aggregated at the sub-basin level and routed through the stream network to the main channel to indicate the total runoff for the river basin. In this study, we use simulations of the existing, extensively calibrated and validated SWAT model of the Vistula and Odra river basins (VOB), (Piniewski et al., 2017a). Piniewski et al. (2017a) conducted a multisite calibration (1991-2000) in 80 non-nested catchments $\left(461-2620 \mathrm{~km}^{2}\right)$ in Poland used as "benchmark" catchments. In the second step they clustered benchmark catchments using a large set of hydrological metrics in order to derive homogeneous calibration areas, from which calibrated parameters could be transferred to non-calibrated catchments 
168 regarding their hydrological similarity. Similar approach with transferring the parameters 169 between sub-catchments regarding their geo-environmental similarities was performed by 170 Choubin et al. (2019). VOB model has been validated in 30 catchments for period 2001-2010. 171 The SUFI-2 algorithm (Abbaspour et al. 2004) within the SWAT-CUP version 5.1.6.2 software 172 package was used for SWAT model calibration, sensitivity and uncertainty analysis. They used 173 Kling-Gupta efficiency (KGE) as an objective function. In this study we used the simulated daily 174 streamflow data (in $\mathrm{m}^{3} / \mathrm{s}$ ) for the sub-catchment (extracted from VOB model) within which the 175 Osowiec gauging station is located. Due to the fact that this particular sub-catchment was not 176 subject to calibration and validation in VOB model, we calculated the KGE and $\mathrm{R}^{2}$ statistics to 177 validate the SWAT model simulation accuracy vs observations in this sub-catchment. SWAT 178 model performance as well as goodness-of-fit measures are presented in Figure 2. It is worth 179 noting that the SWAT model performs well in terms of streamflow simulation for both high and 180 low flows for wet and dry years. The SWAT model captures the characteristic behavior of the 181 catchment in which high spring flows are mainly determined by snowmelt processes. Figure 2B 182 clearly shows that a thicker snow cover in winter correlates with a higher flow in spring. Also, a

183 high annual precipitation causes an increase in low flows (Fig. 2A) which is especially evident in 1842010 (one of the wettest years in Poland over the last few decades).

\section{Climate change scenarios}

186 In this study, the SWAT was driven by climate forcing data from the Climate Change Impact 187 Assessment for Selected Sectors in Poland (CHASE-PL project) Climate Projections: 5-km 188 Gridded Daily Precipitation \& Temperature Dataset (Mezghani et al., 2016), consisting of nine 189 bias-corrected General Circulation Model - Regional Climate Model (GCM-RCM) runs 190 (involving four different GCMs and four different RCMs) provided within the Coordinated 191 Downscaling Experiment - European Domain (EURO-CORDEX) experiment projected to the 192 year 2100 under Representative Concentration Pathway (RCP) 4.5 and RCP 8.5 (Piniewski et al., 193 2017). All bias-corrected values (quantile mapping method by Norwegian Meteorological 194 Institute, (Gudmundsson et al., 2012)) of precipitation and air temperature were available for 195 three time periods: 1971-2000 (historical period), 2021-2050 (near future - NF), and 2071-2100 196 (far future - FF).

197 The projected mean annual temperature in the Biebrza catchment is expected to rise by 198 approximately $1.2^{\circ} \mathrm{C}$ in the $\mathrm{NF}$ and $2{ }^{\circ} \mathrm{C}$ in the $\mathrm{FF}$ under the RCP4.5, with notable seasonal 199 variation: higher change in winter $\left(2.5^{\circ} \mathrm{C}\right.$ in $\left.\mathrm{FF}\right)$ and lower in summer $\left(1.7^{\circ} \mathrm{C}\right.$ in $\left.\mathrm{FF}\right)$. For the $200 \mathrm{RCP} 8.5$, the temperature increase reaches a mean of $3.6^{\circ} \mathrm{C}$ in $\mathrm{FF}$, whereas in $\mathrm{NF}$, it is similar to $201 \mathrm{RCP} 4.5\left(1.3{ }^{\circ} \mathrm{C}\right.$ versus $\left.1.1{ }^{\circ} \mathrm{C}\right)$. The River Biebrza catchment is expected to receive more 202 precipitation in the future in all seasons (with a much higher increase in winter and spring). In 203 the RCP4.5 scenario, the projected annual mean precipitation increase is approximately $6 \%$ in $204 \mathrm{NF}$ and 10\% in FF, while for RCP8.5, the projections show a 16\% increase in FF (Piniewski et 205 al., 2017).

206 We analyzed the mean multi-annual values of investigated flood characteristics for each 207 combination of RCP-time horizon-climate model and presented the results in boxplots. We also 208 carried out a mean annual trend analysis. The statistical detection of the trends was carried out on 
209 three types of datasets: (i) annual peak flows above $25 \mathrm{~m}^{3} / \mathrm{s}$ (in $\mathrm{m}^{3} / \mathrm{s}$ ), (ii) duration of the highest 210 annual floodwaves above $25 \mathrm{~m}^{3} / \mathrm{s}$ (in days), (iii) volume of the highest annual floodwaves above

$21125 \mathrm{~m}^{3} / \mathrm{s}$ (in $\mathrm{m}^{3}$ ); these datasets (i-iii) were considered for two RCPs: (a) RCP4.5 and (b) RCP8 212 and for three time horizons: (1) 1971-2000 (historical period), (2) 2021-2050 (near future - NF),

213 and (3) 2071-2100 (far future - FF). SWAT simulated time-series in the Osowiec gauging station, 214 including flows above $25 \mathrm{~m}^{3} / \mathrm{s}$ are available in the raw data (Discharge-model file) separately for 215 each season (winter, summer), time horizon (NF, FF) and RCP (4.5, 8.5).

\section{Trend analysis by means of statistical models - the method}

217 To address the variability or regular trends of the river regime in the near future we employed the 218 methodology developed for normally distributed datasets by Strupczewski and Kaczmarek (1998, 219 2001) and later extended to non-normally distributed datasets by Strupczewski et al. (2016). This 220 methodology allows for estimation of the quantitative trends simultaneously in mean and

221

222

223

224

225

226

227

228

229

230

231

232

233

234

235

236

237

238

239

240

241

242

243

244

245

246

247

248 standard deviation in SWAT simulated hydrological datasets (SWATmodel_QtimeSeries file in the supplementary materials). A thorough description of this methodology would fall beyond the scope of this paper, and can be found in Strupczewski and Feluch (1998), Strupczewski and Kaczmarek (1998, 2001) and Strupczewski et al. (2001, 2016). However, the basics of this methodology deserve a few comments. The method involves the assumption that the annual river peak flows constitute mutually independent random variables and are the only source of information on the variability of hydrological processes. This means that the proposed approach does not consider the variability of climatic pressures, anthropogenic changes in the catchment and diversity in the regime resulting from water management policy in the modelled catchment. To be clear, we are perfectly aware that all these factors do influence the water flow in the rivers, but the statistical modelling method we used in our study concentrates on the results of these impacts forwarded to the river's response and expressed in the annual peak flows datasets. We consciously resigned from non-parametric trend-detecting tests (e.g. Mann-Kendall Test For Monotonic Trend, Mann 1945, Kendall 1975, Gilbert 1987) because they perform well when the changes are significant and the datasets have no long gaps in the time series (Hirsch et al., 1982). The gap-years in the data series occur when no discharge above $25 \mathrm{~m}^{3} / \mathrm{s}$ is recorded (i.e. no flood occurred) for that particular year; this is especially visible for the winter season, where gaps may last several subsequent years.

The proposed method consists of estimating the time-dependent parameters of selected statistical models by means of the maximum likelihood (ML) estimation method. The best statistical model was selected from 7 competing statistical distribution functions:

a) two-parameter distribution functions: Normal (N), Gumbel $(\mathrm{Gu})$,

b) three parameter distribution functions: Log-Normal (LN), Pearson type 3 (Pe), Generalised Extreme Value (GEV), Generalised Log-Logistic (GLL) and Weibull (We).

These distributions were selected because of their confirmed applicability to model annual and seasonal peak flows in Polish rivers (see e.g. Strupczewski et al., 2009, 2012, Kochanek et al., 2012). A detailed description of these distribution functions and their properties would be beyond the scope of this paper, however the algebraic forms of these functions and formulas of 
parameter estimation by of maximum likelihood method can easily be found in any statistical or hydrological handbook, e.g. in Rao \& Hamed (2000). The criterion for selecting the best nonstationary statistical model for a given data series can be made by comparing Akaike Information Criterion (AIC) values (Akaike, 1974; Hurvich \& Chih-Ling, 1989).

The majority of the statistical models used in hydrology are characterised by the parameter set, namely location, scale and shape (three-parameter distribution functions). The two-parameter distributions used in this study (Normal and Gumbel) have location and scale parameters only. Although useful in terms of estimation and statistical analysis, these parameters hardly ever have a physical interpretation. What is more, the scale parameter, for example, of one distribution function usually means something else than in another distribution function. In order to enable easy comparison between the results provided by each of the competing statistical models, their original sets of parameters (two or three, depending on the statistical model) of each distribution function were replaced by the statistical moments which are the usually non-linear functions of the regular parameters. This re-parametrisation of the distribution functions provides an opportunity to introduce the trends explicitly into the statistical moments, which complies with the common and intuitive methods of trend analysis.

We assumed that time variability will be introduced into the two first statistical moments, i.e. mean $\left(\mu_{t}\right)$ and standard deviation $\left(\sigma_{t}\right)$, and that the third parameter, usually the shape parameter (if it exists), will be time independent. In consequence, the likelihood equations contain both time $(t)$ dependent mean $\left(\mu(t)=m_{t}\right)$ and standard deviation $\left(\mu_{2}(t)^{1 / 2}=\sigma_{t}\right)$, so they would be solved jointly. In fact, one can assume any kind of $m_{t}=f(t)$ and $\sigma_{t}=g(t)$ functions, depending on the time series, however the most common is the assumption of the linear dependence of the process on time:

$$
m_{t}=a \cdot t+b
$$

$$
\sigma_{t}=c \cdot t+d
$$

where $a, b c$ and $d$ - coefficients.

Note that in such notation $a$ in mean and $c$ in standard deviation are the trend coefficients. Therefore, to estimate the trends in mean and standard deviation by means of the maximum likelihood method we have to estimate 5 (for three-parameter distribution functions) or 4 parameters (for two-parameter distribution functions), i.e. $a, b, c, d$ and $k$ which is the shape parameter (if this exists). From a practical point of view, estimation of the parameters by the maximum likelihood method consists of solving a system of 5 non-linear equations (Eq. 1.) which can only be solved by numerical methods. 
282

$$
\left\{\begin{array}{l}
\frac{\partial \ln L}{\partial a}=0 \\
\frac{\partial \ln L}{\partial b}=0 \\
\frac{\partial \ln L}{\partial c}=0 \\
\frac{\partial \ln L}{\partial d}=0 \\
\frac{\partial \ln L}{\partial k}=0
\end{array}\right.
$$

Eq. 1

283

284

285

286

287

288

289

290

291

292

293

294

295

296

297

298

299

300

301

302

303

304

305

306

307

308

309

where:

$$
\begin{aligned}
& \ln L=\sum_{i=1}^{N} \ln f\left(x_{i}, a, b, c, d, k\right)-\text { logarithm of the likelihood function } \\
& f\left(x_{i}, a, b, c, d, k\right) \text { - probability density function (statistical model) } \\
& a, b, c, d, k \text { - parameters of the statistical model (to be estimated) } \\
& x_{i} \text { - elements of the sample } \\
& N \text { - number of elements in the sample }
\end{aligned}
$$

We developed software for estimating the linear trends in mean and standard deviation in seven distribution functions (Strupczewski et al, 2016). Apart from the values of the parameters that provide the maximum rate of the likelihood function, the software output also provides the values of the AIC that enable us to choose the statistical model that best suits the dataset used for calculation. The software is able to cope with the measurement gaps, provided that the spaces in datasets do not exceed a few missing values.

\section{The impact of hydrological changes on the wetland ecosystems}

In the Lower Biebrza basin extents and durations of floods are considered key drivers of riparian ecological processes. Because our hydrological analyses are being developed for the Osowiec water gauge it is therefore necessary to find a link between the analysed flood characteristic at this gauge and floodplain inundation features. The relationships between annual maximum discharge and spatial range of the inundation waters as well as the duration of inundations and floodwave duration observed in the Osowiec gauge were developed based on the results of the 1D hydrodynamic flow model. This model and its results coupled with GIS analysis (inundation maps) were descripted in details in the Chormański article (Chormanski et al., 2009). The maximum flood extent (defined as the number of flooded pixels in digital elevation model DEM) for the daily time series from 1961 to 1996 and the duration of inundation in different plant communities (Fig. 1) in this period were used to analyse the relationship between these characteristics and variables observed for the Osowiec water gauge. Due to the importance of typical floodplain ecosystems and its biodiversity we in our analysis concentrate on Caricetum appropinquatae (CA), Caricetum gracilis (CG), Glycerietum maximae (GM) and Phragmitetum 
310 communis (PC) (Fig 1.) A qualitative description of expected changes in ecosystems resulting 311 from the estimated hydrological changes was carried out by comparing the estimated future

312 hydrological and other environmental characteristics with typical conditions as observed in the

313 distinguished vegetation communities and reported in literature.

\section{Results}

315 Inter-comparisons of SWAT model-based simulations of selected flood characteristics (i.e. 316 duration, volume and maximum discharge) concerning the RCP and time horizon are presented 317 separately for winter and summer seasons (Fig. 3 and 4). Such a distinction is dictated by the 318 diverse genesis of floods, with the dominant role in their formation being played by melting 319 snow in spring and rainfall in summer. For flood duration, a significant increase is projected, 320 with a significant rise in the ensemble median from 80 days in the historical period to 105 and 321135 in NF and FF, respectively, for RCP4.5. The increase escalates in RCP8.5 to 135 and 170 for $322 \mathrm{NF}$ and FF, respectively. A similar pattern is observed for flood volume, which increases with 323 the time horizon and RCP. The ensemble median increases from 8 billion $\mathrm{m}^{3}$ in the historical 324 period to 12 billion $\mathrm{m}^{3}$ in NF and 21 billion $\mathrm{m}^{3}$ in FF for RCP4.5, and for RCP8.5 to 21 and 42 325 billion $\mathrm{m}^{3}$ for $\mathrm{NF}$ and FF, respectively. However, this increase is mainly a result of the flood 326 duration rather than the maximum discharges, which even tend to slightly decrease in the future 327 (Fig. 3). The duration and volume of summer floods seem to follow the same pattern as for the 328 winter season, although the magnitude of increase is much lower. For flood duration, the 329 ensemble median increases from 8 days in the historical period to 20 and 29 in NF and FF, 330 respectively, for RCP4.5. For RCP8.5, the flood duration increases to 21 and 60 days for NF and 331 FF, respectively. There is a slight difference in maximum discharge noted for the summer season 332 compared to winter floods, as high flows increase with the time horizon and RCP. Comparing 333 the values, the ensemble median of maximum flow increases from $25 \mathrm{~m}^{3} / \mathrm{s}$ to $39 \mathrm{~m}^{3} / \mathrm{s}$ and 41 $334 \mathrm{~m}^{3} / \mathrm{s}$ for NF and FF, respectively. Comparing the RCPs, in this case the differences are negligible.

335 The preliminary calculations described in the previous chapter revealed that a certain dataset, i.e. 336 annual maximal discharges, volume of the floodwaves and residence time tend to be represented 337 by particular dominating statistical models. For instance, the datasets based on the maximum 338 discharges are often appointed by the AIC to the group of the extreme value distribution 339 functions (statistical models). In consequence, most often these are the Gumbel (Gu) or Log340 Normal (LN) distribution functions which were predominately selected as the best for modelling 341 such datasets, but in few cases the Normal $(\mathrm{N})$ distribution function proved to be the best 342 according to the AIC. Even though the criterion of the AIC occasionally pointed to another 343 statistical model (e.g. GEV or We), the differences between the AIC values for the best statistical 344 model (i.e. GEV or We) and the Gumbel one (usually the second in the competition) were 345 negligible. Therefore, for brevity we decided to apply the Gumbel or Log-Normal statistical 346 models (depending which of the two prevailed) to the datasets of annual peak flows. Similarly, 347 the volume datasets are best described by the Gumbel or Log-Normal distribution functions. For 348 the data of flood wave duration (in days) three statistical models, i.e. Normal, Gumbel or Log349 Normal distribution functions, are most often indicated as suitable for the samples. Consequently 350 the list of 7 potential statistical models to choose from was reduced to the two two-parameter and 
one three-parameter distribution functions whose parameters are relatively easy to estimate (in terms of numerical calculations). On top of that, there is no need to estimate an additional shape parameter for two-parameter statistical models. This attempt to reduce the number of parameters to be estimated is a consequence of the general principle of avoiding the 'overparameterisation' of hydrological models and results in a reduced risk of numerical errors when optimizing the likelihood function (the larger the number of parameters, the higher the risk of algorithm failure). Note that all the calculations were carried out separately for summer and winter seasons, so the results were summarised in two thematic pairs of diagrams: Figures 5 and 6 for the summer, 7 and 8 for winter floods.

First we calculated the mean and standard deviation values for the mid-term year (i.e. the $14^{\text {th }}$ year of the series) of the analysed 27-year data series (with gaps) in the baseline and subsequent RCP4.5 and RCP8.5 scenarios. The mid-term values of the mean $\left(m_{14}=a \cdot 14+b\right)$ and standard deviation $\left(\sigma_{14}=c \cdot 14+d\right)$ for the maximum discharge, duration and volume of the floodwave provide the base and summarising information about the possible changes of the particular properties of the floodwaves measured and modelled within the time. Of course, the estimation parameters allow the mean and standard deviation to be calculated for any time $t$ within the dataset time frame, and also extrapolate them outside the time frames when necessary. However, extrapolation is not recommended far beyond the periods considered in the time series used for estimation, because this may lead to erroneous conclusions. Figures 5 and 7 illustrate the progress in the expected values and variability of maximum discharge, duration and volume for summer and winter seasons, respectively. The diagrams represent the median (thick solid line) and the distribution of the SWAT modelling results - the lower $\left(1^{\text {st }}\right)$ and upper $\left(3^{\text {rd }}\right)$ quartiles (dashes) of the mid-term values calculated for 9 climate models. The first 3 years were deducted from each dataset due to this being the warm-up time, so that the climatic models would adjust and produce credible results.

The values of the trends themselves provide information about the stability of a particular floodwave parameter within a 27-year data series. The results of the trend calculations are presented by box-whisker diagrams in Figures 6 and 8. The box-whisker plots in the concise but informative graphic form show the basic summary statistics of trends in all 9 climate models, i.e. median - thick solid line in a box, the distribution of the SWAT modelling results for 9 climate models - the lower $\left(1^{\text {st }}\right)$ and upper $\left(3^{\text {rd }}\right)$ quartiles are visualised by the bottom and top edges of the boxes, respectively, minimum and the maximum values - lower and upper whiskers, respectively, and outliers visualised by the circles. Each plot presents the situation for a different climatic scenario (RCP4.5 and RCP8.5) and for a different period in time (baseline, NF and FF). The graphs depict the relative trends in mean value and standard deviation (in \%) for all three datasets. The trends $(a$ or $c)$ in time dependent mean $\left(m_{t}=a \cdot t+b\right)$ and standard deviation $\left(\sigma_{t}=c \cdot t+d\right)$ refer to the intercept parameters $b$ and $d$, respectively, denoting the mean value and the standard deviation for $t=0$. Such a relative presentation of the trends offers a possibility to analyse the effective trends in mean and standard deviation.

\section{Case A. Summer season - Figures 5 and 6}


391 The summary statistics (visualised by the diagrams) confirm the analysis of datasets presented in 392 previous paragraphs. To avoid repetition, we will concentrate on the variability of the basic 393 summary statistics of the results from the 9 climate models rather than on their values (these are discussed in previous paragraphs, see also Figures 3 and 4).

395 The mid-term mean values of maximum discharge, duration and volume rise with each subsequent time frame (Fig. 5 A-C). Moreover, the rise in mean is steady and consistent and can be observed for both RCP scenarios. Judging by the medians, it can be noticed that the rise is generally significant in the subsequent time frame for all the floodwave properties, i.e. maximum discharge, duration and volume. For instance, the rise in median of the mid-term mean maximum discharges between baseline and $4.5 \mathrm{NF}$ periods is slightly over $6 \%$, between $4.5 \mathrm{NF}$ and $4.5 \mathrm{FF}$ some go to nearly $16.4 \%$, whereas for RCP 8.5 these steps are $12 \%$ and $24 \%$ high, respectively. The comparative step in medians of the mid-term means between the subsequent time horizons is at least 2 times higher in duration, and even 9 times higher in volume than in maximum discharge. This means that a relatively gradual increase in maximum peak flows (a few percent over a decade) may result in sudden future expansion of the duration and volume of the floodwaves. In general, the quartile values for the mid-term mean are similar to the medians, and their variability around the median does not exceed $+/-50 \%$, except volume, which can even exceed $+400 \%(4.5 \mathrm{NF})$.

Note that it is not only the time-dependent mean that influences the value of a time-dependent parameter, but the time-dependent standard deviation should also be considered (Fig. 5 D-F). However, the situation with the mid-term standard deviation of particular floodwave parameter is more complicated. In general, the median values of the standard deviation are comparable to the values of the mean medians for maximum discharge and duration, whereas they are ca. ten times smaller in the case of floodwave volume. Furthermore, it is impossible to distinguish one single direction for the changes in the mid-term standard deviation with time, because e.g. the median of the standard deviation of the maximum discharge always rises for the scenario RCP4.5 (ca. by $30 \%$ every $\sim 30$ years), whereas it drops by $8.5 \%$ between the baseline period to the NF time window and rises again by $55 \%$ to FF in the RCP 8.5 scenario. Such instability in both the magnitude of the difference in subsequent periods and the direction of change can also be observed for duration and volume, but these do not follow the patterns seen in maximum peak flows. This means that the 27 -year time frames are perhaps long enough to observe stable gradual changes in the mean of the floodwave parameter values (not always - see the winter season case), but too short to categorically judge their possible variability range, i.e. standard deviation. The values of the $1^{\text {st }}$ and $3^{\text {rd }}$ quartiles for mid-term standard deviation are comparable with the equivalent mid-term medians.

As far as the relative trends are concerned (Fig. 6), the box-whisker plots for the mean value (Fig. 6 A-C) clearly indicate that the relative trend in mean for the 9 climate models is negligible within subsequent time frames (with the median - thick solid line in a box - closely revolving around $0 \%$ ) in maximum discharge, duration and volume of the flood waves. The data distribution in datasets (the $1^{\text {st }}$ and $3^{\text {rd }}$ quartiles) is also generally minimal when compared to the 431 data range, including the outliers visualised by the circles. This means that both the baseline and 
432 all 4 scenarios point to the relative stability of the extreme waters currently as well as in the 433 nearest and further future. The only exception concerns the case of flood volume in the scenario 434 of $8.5 \mathrm{FF}$, where the relative trend in mean reaches nearly $20 \%$, which is probably caused by the

435

436

437

438

439

440

441

442

443

444

445

446

447

448

449

450

451

452

453

454

455

456

457

458

459

460

461

462

463

464

465

466

467

468

469

470

471 projected disproportional increase of the floodwave volume. It is interesting that the resulting graphs are accompanied by distant outliers (especially in duration plots), supporting the idea of great variability of the scenario results created by 9 climate models used in calculations.

Figure 6 D-F represents the distribution of the trend in standard deviation in the summer season statistical modelling results. Here, too, the relative trend revolves around $0 \%$ for all the cases considered, except Volume 8.5FF in the floodwave volume results, where the relative trend is comparable to the result for the mean value. The distribution of the results is also small - the quartiles reach a maximum of $20 \%$, although a higher range of outliers can be seen, exceeding $500 \%$ (for the flood wave duration baseline data). Please note, however, that the short datasets used for estimation and the unambiguous results for mid-term standard deviation suggest that the results concerning trends in standard deviation may be affected by a significant (and unknown) level of uncertainty.

\section{Case B. Winter season - Figures 7 and 8}

The basic summary statistics of the mid-term parameters for the winter season are presented in Figure 7. The median of the mid-term mean of the duration and volume of the floodwaves increases in each time window for both the 4.5 and $8.5 \mathrm{RCP}$ scenarios (Fig. $7 \mathrm{~A}-\mathrm{C}$ ). The magnitude of this growth varies, however, and ranges from e.g. $6.5 \%$ (duration $4.5 \mathrm{NF}$ to $4.5 \mathrm{FF}$ ) to over $40 \%$ (volume $8.5 \mathrm{NF}$ to $8.5 \mathrm{FF}$ ), but usually revolves around $20 \%$ (for consecutive time periods). Unlike duration and volume, the mid-term mean tendency for the annual maximum discharges is not monotonic within the entire period considered. The median rises slightly (by $1.3 \%$ and $2.7 \%$ from baseline to NF, for RCP4.5 and RCP8.5, respectively) and then in FF falls slightly by $5.7 \%$ and $7.4 \%$ for RCP4.5 and RCP8.5, respectively. Considering the significant range of uncertainty, the mid-term mean annual peak discharges are fairly stable. The upper and lower quartiles for all the floodwave parameters are of a similar value as the median, and they rise by a few percent per decade, which is expected because the uncertainty (and thus the range of the models results) grows with the time distance into the future. To sum up, the results for the mid-term values conform with the analysis depicted in previous chapters (compare Figure 4).

It is hard to distinguish one monotonicity pattern for the median of the mid-term standard deviation of particular floodwave parameters (Fig. 7 D-F), because it differs not only from parameter to parameter (which can happen), but also between time periods. In addition, the variability of the medians is high, from $-137 \%$ in volume from baseline to NF, RCP8.5 to $+26 \%$ in volume from $8.5 \mathrm{NF}$ to $8.5 \mathrm{FF}$. The upper and lower quantiles are comparable to the medians, and they increase gradually with the subsequent time series but at a different rate (from $1 \%$ to $37 \%$, depending on the floodwave parameter and periods).

As in the case of the summer season, for most of the modelling results and baseline data the relative trend in mean value is small and close to $0 \%$ (Fig. 8 A-C). Moreover, it is characterised by generally smaller diversity than can be observed in the summer season. The $3^{\text {rd }}$ and $1^{\text {st }}$

Peer] reviewing PDF | (2020:02:45694:2:0:NEW 27 Jul 2020) 
472 quartiles do not exceed $2 \%$ above or below the median value. In addition, the outliers observed 473 are smaller, apart from volume, where they are nearly $-120 \%$ high for $8.5 \mathrm{NF}$. All these factors 474 suggest stability of the trend in mean value regardless of the projected scenario.

475 The pattern revealed in the graphs for the mean is repeated in the plots for standard deviation

476 (Fig. 8 D-F). The trends are relatively small - close to $0 \%$ and their distribution is practically 477 negligible for all scenarios, suggesting stability of the amplitude of extreme flows in the analysed 478 cross-section.

479 Figure 9 shows the relationship between maximum discharge $\left(\mathrm{Q}_{\max }\right)$ at Osowiec gauge and 480 maximum flood area, estimated on the basis of the results for the period 1961-1996 described in 481 Chormański et al. (2009). Average time (days) of inundation in LBB vegetation communities 482 (Fig. 1) vs. duration of flood at Osowiec gauge are shown in Figs. 10-13. This analysis (Fig. 9) 483 revealed a functional relationship between maximum inundation area and $Q_{\max }$. The two outliers 484 are related to the maximum inundation in this area that occurred in 1979 and the minimum value 485 of $Q_{\max }$ in the time series that was recorded in 1984. The relationship between the duration of 486 peak flows and the average duration of inundation in the abodes of Caricetum appropinquatae 487 (CA), Caricetum gracilis (CG), Glycerietum maximae (GM), Phragmitetum communis (PC) 488 indicates a strong linear relationship with the correlation coefficients $R=0.977,0.906,0.827$, 4890.865 , respectively.

490 The lower values of the correlation coefficient $R$ (time of inundation vs. duration of flood) for 491 GM and PM communities probably may result form a larger spatial heterogeneity in elevation within these communities (Fig. 1) but also from the uncertainty of the modelled flood-water table in the valley stemming from use of the 1D unsteady flow model (by Chormanski et al., 2009) and the insufficient resolution of the DEM. However, on a landscape scale it has been shown that river floods, water quality and vegetation are strongly interlinked in the Biebrza floodplains (Keizer et al. 2016).

\section{Discussion}

499

In the current study, we estimated the mean changes of flood indices (30-year mean values) in the near and far future (NF and $\mathrm{FF}$ ) with respect to the reference period (Baseline). It is widely recommended to use a 30 year period in describing the impact of climate change, as it takes approximately 30 years for any difference between current emission scenarios to have an noticeable impact on the climate (Carter, 2007). Such an approach is commonly used in climate change impact studies instead of long-term trend analyses which are characterized by nonstationarity (Meresa et al., 2017; Razavi et al., 2016). Furthermore, for a proper consideration of climate impacts the sub-periods analysed should not contain clear trends. In this study an annual trend analysis of selected flood indices was therefore performed for each of the projection periods (Baseline, NF and FF). The statistical analyses (Figs. 5-6) indicate that no significant trends occur in the time series of the duration and volume of floods or in their culmination in the historical period and future projections, which could be caused by a gradual increase or decrease in the value of these indicators as a result of climate pressure. For comparison, the results

511 obtained by Maksymiuk et al (2008) for the Burzyn water gauge (closing the River Biebrza's 
512 Lower Basin) indicate that the trend in maximum annual discharges was negligibly decreasing in

513 the period 1966-2003.

514 The results presented in this study clearly indicate that both volume and duration of winter floods 515 will increase continuously with the time horizon and from RCP4.5 to RCP8.5. At the same time, 516 the reduction in peak annual floods is expected to decline slightly in all scenarios. Duration and 517 volume of summer floods seem to follow the same pattern as for the winter season, however, the 518 projected magnitude of increase is much lower. Such a discrepancy in hydrological response is 519 most probably caused by the expected precipitation and temperature changes. In the future time 520 horizon, precipitation is expected to increase more intensively in winter compared to summer. 521 Additionally, temperatures in winter season are set to increase causing a decrease in snowfall and 522 consequently a reduction in the volume of water originating from snow thawing during the 523 spring. This explains the reduction of peak flows usually occurring during the spring thaw in the Biebrza catchment. A slight increase in precipitation and temperature during the summer season causes an increase in evapotranspiration and consequently the overall increase in summer floods is moderate.

527 In this study, flood characteristics (duration, volume and maximum discharge) were analyzed in 528 terms of different emission scenarios and time horizons. A similar investigation has been 529 conducted on a different scale (Europe) by Schneider et al. (2011). In their study, the authors 530 assessed flooding by quantifying the changes in magnitude, timing and duration of overbank 531 flows for major European rivers affected by climate change, using the global scale hydrological 532 model WaterGap (Water-Global Assessment and Prognosis) run by three climate change 533 projections (IPCC SRES - Special Report on Emissions Scenarios - A2 and the SRES B1) for the 534 year 2050. Their results show that for Central and Eastern Europe, flood volume causing floodplain inundation is expected to be reduced in the 2050s. A similar outline is drawn for flood duration which also seems set to decline in the future. In another study by Schneider et al. (2013), a decrease in flood volume was predicted for inundation and duration of overbank flows in Central and Eastern European rivers. In addition, projections carried out by Dankers and Feyen (2008) found a significant decrease in the occurrence of flood hazards in the northeast of Europe.

540 It is noteworthy that the current study presents opposite results i.e. volume and duration of floods 541 are projected to increase continuously in the future time horizons. It must be noted that there are numerous reasons why hydrological projections differ, so a direct comparison to other studies is usually hampered with methodological differences (Kundzewicz et al., 2017) - first of all, the scale of the hydrological model, which in the case of Schneider $(2011,2013)$ and Dankers and Feyen (2008) covered the whole European continent, compared to the catchment scale Vistula and Odra Model. The model scale directly entails the resolution of climate change projected data, and hence, results for the Biebrza Valley presented in the scale of the whole European continent 548 is far more uncertain In addition, the climate models themselves vary significantly according to 549 the GCM/RCM used and the downscaling method applied. Dankers and Feyen (2008) used only 550 one RCM, whereas Piniewski et al. (2017) used 9 RCMs and draw conclusion based on their 551 median response. 
552 Our results revealed that for the three considered time periods, i.e. 1971-2000 (historical period) 553 and future projections 2021-2050 (NF), 2071-2100 (FF), the trends in mean and standard 554 deviation related to the respective base values (see Figs. 6 and 8) in the time series of the

555

556

557

558

559

560

561

562

563

564

565

566

567

568

569

570

571

572

573

574

575

576

577

578

579

580

581

582

583

584

585

586

587

588

589

590

591

592

593 duration and volume of floods or in their culmination are close to zero percent. It means that these hydrological parameters of floodwaves are expected to remain fairly stable and no noticeable increase or decrease in these parameters is anticipated. In consequence, this implies that the wetland is not under threat from climate change in the sense that the wetland will disappear or transit to a fundamental other state (dryer, wetter) which can be regarded as good news for the stability of the floodplain ecosystem as a whole in the Lower River Biebrza Basin. This is an important finding suggesting that sustainable preservation of the wetland is likely from a hydrological perspective and that the function as an important stopover site for migratory birds related to wetlands will continue (Budka et al., 2019; Maciorowski et al., 2014; Polakowski et al., 2018).

However, the risk of malfunctioning of riparian wetlands is associated with an almost twofold increase in the duration of summer inundations, which increases with the time horizon (a greater increase in the distant future than in the near one, (Fig. 4). The duration and volume of winter floods seem to follow the same pattern as for the summer season (Fig.3). Figures 10-13 indicate that the durations of inundation in plant communities in the Lower River Biebrza Basin are strongly correlated with the duration of flood monitored at the Osowiec gauge. This implies that all of these plant communities will face a significant change in duration and inundation depth both during winter and summer inundations. Apart from changes in habitat conditions (Kotowski et al. 2006) this will hamper the possibility for mowing and harvesting of hay from wetlands. Timely mowing is particularly important to preserve low nutrient availability and low growing herbaceous vegetation (Olde Venterink et al. 2009). Failure to mow in large areas of open peat bogs may result in a succession of shrubs and forest communities (Piórkowski, 2003), which would consequently transform the open marshes of floodplains towards ecosystems with lower biodiversity. The disappearance of valley meadows that could be maintained by continuing periodic mowing (Mioduszewski, 2004) would also result in the loss of rare wetland birds such as Aquatic Warbler, Ruff, Great Snipe and Greater Spotted Eagle. However, it should be noted that although seasonal mowing is a positive management factor for the biodiversity of nonforested wetlands, analysis of the effects of rotational wetland mowing on breeding birds provided evidence for a positive effect on some wetland birds of significantly longer mowing intervals (Antoniazza et al., 2018).

Grygoruk et al. (2014) assume for the time horizon 2070-2100 a significant increase in precipitation in summer, a decrease in precipitation in autumn, winter and spring and a general increase in the average air temperature and on this basis, they present hypothetical scenarios of changes in flood condition and their ecological consequences in the Lower River Biebrza Basin. These assumptions were made on the basis of the GCM-RCM (combined with the SRES A1B emission scenario) projections on temperature and precipitation changes. Contrary to this hypothetical approach, in our research we used flow hydrographs simulated with the calibrated and validated SWAT model and considering nine bias-corrected climate models with the modern generation emission projections (RCP) 4.5 and 8.5. 
594 The increase in maximum discharges observed for summer floods in both the near and distant 595 future (Fig. 4) leads to an increase in flood extent (Fig. 9). This may lead to extension of the zone 596 of flood tolerant communities, such as Phragmitetum, Glycerietum maximae and Caricetum 597 gracilis on cost of less flood tolerant communities such as Caricetum appropinquatae and 598 Calamagrostietum strictae. If the flood zones would extend in prolonged periods to the valley 599 edge moss-sedge communities such as Scorpidio Caricetum elatae and Caricetum rostrato600 diandrae might disappear (Palczynski 1984; indicated in Fig. 1 as mixed sedges and mixed 601 sedges and grasses). In such a case these ecologically valuable low sedge meadows might be 602 displaced by taller growing sedges that have a larger tolerance to prolonged flooded conditions 603 (Wassen et al., 2002), which in consequence would lead to loss of mosses, forbs and low sedges 604 and transformation towards more productive ecosystems of lower biodiversity (Palczynski \& 605 Stepa, 1991; Swiatek et al., 2008).

606 The extension of the duration of inundations while temperatures are increasing as spring 607 advances is expected to lead to higher nutrient availability, since the turnover of organic matter is 608 expected to increase in warmer standing water (Wassen et al. 2006). Currently already algal 609 blooms occur during spring inundations when spring temperatures are relatively high (personal 610 observation Wassen). This may occur more frequently in future leading to decreased 611 transparency of the flood water which in turn may hamper the growth of mosses and forbs that 612 normally start growing while inundations still occur. The increase in nutrients may also be 613 dangerous for fish, because when coinciding with a surge in higher flow durations, the excess of 614 nutrients can inhibit fish reproduction. The nearly double duration of winter inundations (a 615 greater increase was observed in the distant than in near future) (Fig. 3) may also hinder the 616 removal of bushes (which is normally done in winter season) and cause difficulty in 617 mechanically mowing in large swamp areas, which in turn is expected to lead to loss of typical 618 herbaceous floodplain vegetation.

619 On the other hand, the extension of the duration and volume of floods (which occurs both in 620 winter and summer inundations) is a positive phenomenon because it stretches the period of 621 watersaturated and moist conditions of hydrogenic habitats and prevents over-drying. 622 Dropdowns in water tables in the floodplain in the growing season were shown to be highly 623 correlated to a boost in nitrogen release (Wassen et al 2002; Wassen \& Olde Venterink 2006). 624 Thus, if water saturated conditions prevail longer in summer, we expect nitrogen availability to 625 decrease. Furthermore, prolonged inundation will slow down decomposition of plant remains and prevent degradation of the peat substrate, which is of great importance for maintaining the functioning of the wetlands especially the fens on largely organic substrate (Mirosław_Swiatek et al., 2017). Moreover, the accumulation of peat may increase when water saturation extends over longer periods.

630 The results of statistical analyses quantifying the impact of climate pressure on selected 631 hydrological indices of floods (duration, maximum flows, volume of floods) imply that the 632 effectiveness of the swamp, marsh and fen ecosystem management may be limited due to a 633 failure to adapt these activities to climate change, and that new methods may need to be 
634 introduced to protect nature in the area of the lower River Biebrza basin (Grygoruk and Svenn, 635 2017).

\section{Conclusions}

637 The trend analysis of mean and standard deviation of peak flows, floodwave duration and 638 volume for both observed and modelled scenarios revealed negligible tendencies in the 639 scrutinised datasets for the summer and winter hydrological seasons within the three time 640 windows analysed. This implies that the wetland is relatively stable under climate change.

641 The results presented in this study clearly indicate that both volume and duration of winter floods 642 will increase continuously with the time horizon and intensification of RCP. At the same time, 643 the reduction in peak annual floods is expected to decline slightly in all scenarios. Duration and 644 volume of summer floods seem to follow the same pattern as for the winter season, however, the 645 projected magnitude of increase is much lower.

646 Despite the fact that statistical analyses showed no trend of the hydrological characteristics 647 analyzed (maximum discharge, duration and volume) within the analyzed time windows, the 648 increase in flood duration as a consequence of climatic pressure in the near (2020-2050) and 649 distant (2070-2100) future points to the possibility of difficulties in maintaining the natural 650 diversity and agricultural use of wetlands in the Lower Biebrza Basin. Changes in environmental 651 conditions (e.g. an almost two-fold increase in the duration of floods in the near and distant 652 future) and other environmental changes may lead to considerable shifts in transversal ecosystem 653 zonation with expansion of flood-tolerant communities such as Phragmitetum and Caricetum 654 gracilis on cost of less flood-tolerant communities such as Caricetum appropinquatae and other 655 low-growing sedge-moss communities. Furthermore, nutrient availability and algal blooms may 656 increase during spring inundations but lower turnover of organic matter later in summer may 657 lead to a higher peat accumulation rate. Logistical problems with summer mowing and removal 658 of bushes in winter may prevent the preservation of selected habitats which are under the 659 management of the Biebrza National Park.

\section{Literature}

661 Antoniazza M, Clerc C, Le Nédic C, Sattler T, Lavanchy G. 2018. Long-term effects of 662 rotational wetland mowing on breeding birds: evidence from a 30-year experiment. Biodivers. 663 Conserv. 27:749-763 DOI 10.1007/s10531-017-1462-1

664 Arnell NW, Gosling SN. 2013. The impacts of climate change on river flow regimes at the 665 global scale. J Hydrol 486:351-364

666 Banaszuk H. 2004. General description of Biebrza Valley and Biebrza National Park. In:

667 Banaszuk, H. (Ed.), Biebrza Valley and Biebrza National Park. Wydawnictwo Ekonomia i 668 Środowisko, Białystok (in Polish).

669 Berezowski T, Wassen M, Szatylowicz J, Chormanski J, Ignar S, Batelaan O, Okruszko T. 2018. 670 Wetlands in flux - looking for the drivers in a central European case. Wetlands Ecology and 671 Management 26:849-863 DOI 10.1007/s11273-018-9613-z. 
672 Bootsma MC, Wassen MJ, Jansen AJM. 2000. The Biebrza-valley as an ecological reference for 673 Dutch stream valleys (in Dutch with English summary). Landschap 17:113-130

674 Budka M, Jobda M, Szałański P, Piórkowski H. 2019. Effect of agri-environmental measure for 675 the aquatic warbler on bird biodiversity in the extensively managed landscape of Biebrza 676 Marshes (Poland). Biological Conservation 239:108279 DOI 10.1016/j.biocon.2019.108279.

677 Carter T. 2007. General guidelines on the use of scenario data for climate impact and adaptation 678 assessment- Version 2.

679 Chormański J, Mirosław-Świątek D, Michałowski J. 2009. A hydrodynamic model coupled with 680 GIS for flood characteristics analysis in the Biebrza riparian wetland. Oceanological and 681 Hydrobiological studies 37:1-8.

682 Chormański J, Okruszko T, Ignar S, Batelaan O, Rebel K, Wassen M. 2011. Flood mapping with 683 remote sensing and hydrochemistry: a new method to distinguish the origin of flood water during 684 floods. Ecological Engineering 37:1334-1349.

685 Choubin B, Solaimani K, Rezanezhad F, Roshan MH, Malekian A, Shamshirband S. 2019. 686 Streamflow regionalization using a similarity approach in ungauged basins: Application of the 687 geo-environmental signatures in the Karkheh River Basin, Iran. Catena 182:104128.

688 Costanza R, d'ArgeR, de Groot R, Faber S, Grasso M, Hannon B, Limburg K, Naeem S, 689 O'Neill RV, Paruleo J, Raskin RG, Sutton P, M. van der Belt M. 1997. The value of the world's 690 ecosystems and natural capital. Nature 387:253-260.

691 Costanza, R., de Groot R, Sutton P, van der Ploeg S, Anderson SJ, Kubiszewski I, Farber S, 692 Turner RK. 2014. Changes in the global value of ecosystem services. Global Environmental 693 Change 26:152-158.

694 Dankers R, Feyen L.2008. Climate change impact on flood hazard in Europe: An assessment 695 based on highresolution climate simulations. J. Geophys. Res. 113:D19105.

696 Dorau K, Gelhausen H, Esplor D, Mansfeldt T. 2015. Wetland restoration management under the 697 aspect of climate change at a mesotrophic fen in Northern Germany. Ecological Engineering 698 84:84-91.

699 Finlayson CM. 2013. Climate change and the wise use of wetlands: information from Australian 700 wetlands. Hydrobiologia 708:145-152.

701 Gilbert RO. 1987. Statistical Methods for Environmental Pollution Monitoring, Wiley, NY.

702 Grygoruk M, Biereżnoj-Bazille U, Mazgajski M, Sienkiewicz J, 2014. Climate-induced 703 challenges for wetlands: revealing the background for adaptive management of ecosystems in the 704 Biebrza Valley, Poland. [in]: Rannow S, Neubert M. (eds.) Managing protected areas in Central 705 Europe under climate change. Advances in Global Change Research 58:209-232 
706 Grygoruk M, Rannow S. 2017. Mind the gap! Lessons from science-based stakeholder dialogue 707 in climate-adapted management of wetlands. Journal of Environmental Management 186:108708119.

709 Gudmundsson L, Bremnes JB, Haugen JE, Engen-Skaugen T. 2012. Technical Note: 710 Downscaling RCM precipitation to the station scale using statistical transformations-A 711 comparison of methods. Hydrol. Earth Syst. Sci. 16:3383-3390.

712 Hirsch RM, Slack JR, Smith RA. 1982. Techniques of trend analysis for monthly water quality 713 data, Water Resources Research 18(1):107-121.

714 Hoegh-Guldberg O, Bruno JF. 2010. The Impact of Climate Change on the World's Marine 715 Ecosystems. Science 328:1523-1528.

716 Joosten H, Clarke D. 2002. Wise use of mires and peatlands. Background and principles 717 including a framework for decision making. International Mire Conservation Group, 718 International Peat Society, ISBN 951-97744-8-3.

719 Keizer FM, Schot PP, Okruszko T, Wassen MJ. 2016. Landscape-scale ecohydrological mapping 720 demonstrating how flood inundation water quality types relate to floodplain vegetation 721 communities. Ecohydrology DOI: 10.1002/eco.1746

722 Kendall MG. 1975. Rank Correlation Methods, 4th edition, Charles Griffin, London.

723

724

725

726

727

728

729

730

731

732

733

734

735

736

737

738

739

740
Kiciński T, Byczkowski A. 1983. Częstotliwość i czas trwania zalewów w dolinie Biebrzy [w:] Analiza przyrodniczych i gospodarczych walorów w basenie środkowym Biebrzy. Zeszyty problemowe postępów nauk rolniczych, Zeszyt 255, Warszawa, Państwowe Wydawnictwo Naukowe, str. 75 - 87

Kochanek K, Strupczewski WG, Bogdanowicz E. 2012. On seasonal approach to flood frequency modelling. Part II: Flood frequency analysis of Polish rivers. Hydrological Processes 26(5):717-730 DOI 10.1002/hyp.8178

Kossowska-Cezak U. 1984. Climate of the Biebrza ice-marginal valley. Pol. Ecol. Stud. 10:3-4

Kotowski W, Thörig W, Van Diggelen R, Wassen MJ. 2006. Competition as a structuring factor for wetland vegetation - a reciprocal experiment in a floodplain productivity gradient. Appl. Veg. Sci. 9:231-240.

Kundzewicz ZW, Krysanova V, Dankers R, Hirabayashi Y, Kanae S. 2017. Differences in flood hazard projections in Europe-their causes and consequences for decision making. Hydrol. Sci. J. 62:1-14.

Kundzewicz ZW, Piniewski M, Mezghani A, Okruszko T, Pińskwar I, Kardel I, Hov R̆, Szcześniak M, Szwed M, Benestad R.E, Marcinkowski P, Graczyk D, Dobler A, Førland EJ, O'Keefe J, Choryński A, Parding KM, Haugen JE. 2018. Assessment of climate change and associated impact on selected sectors in Poland. Acta Geophys. 66:1509-1523. 
741 Maciorowski G, Mirski P, Kardel I, Stelmaszczyk M, Mirosław-Świątek D, Chormański J,

742 Okruszko T. 2014. Water regime as a key factor differentiating habitats of spotted eagles Aguila

743 clanga and Aguila pomarina in Biebrza Valley, Bird Study

744 Maksymiuk A, Furmańczyk K, Ignar S, Krupa J, Okruszko T. 2008. Analiza zmienności 745 parametrów klimatycznych i hydrologicznych w dolinie rzeki Biebrzy. Przegląd Naukowy.

746 Inżynieria i Kształtowanie Środowiska 3(41):59-68

747 Mann HB. 1945. Non-parametric tests against trend, Econometrica 13:163-171.

748 Meresa HK, Romanowicz RJ, Napiorkowski JJ. 2017. Understanding changes and trends in 749 projected hydroclimatic indices in selected Norwegian and Polish catchments. Acta Geophys. $750 \quad 65: 829-848$.

751 Mezghani A, Dobler A, Haugen JH. 2016. CHASE-PL Climate Projections: 5-km Gridded Daily

752 Precipitation \& Temperature Dataset (CPLCP-GDPT5). Available online:

753 http://data.4tu.nl/repository/uuid:e940ec1a-71a0-449e-bbe3-29217f2ba31d

754 Mirosław-Świątek D, Michałowski R, Szporak-Wasilewska S, Ignar S, Grygoruk M. 2016.

755 Unraveling uncertainties of water table slope assessment with DGPS in lowland floodplain

756 wetlands. Environmental Monitoring and Assessment 188:625 DOI 10.1007/s10661-016-5642-3

757 Mirosław-Świątek D, Kiczko A, Szporak-Wasilewska S, Grygoruk M. 2017. Too wet and too 758 dry? Uncertainty of DEM as a potential source of significant errors in a model-based water level 759 assessment in riparian and mire ecosystems. Wetlands Ecology and Management 25:547-562 760 DOI 10.1007/s11273-017-9535-1.

761 Okruszko T. 2005. Kryteria hydrologiczne w ochronie mokradeł. Rozprawy Naukowe i 762 Monografie. Wydawnictwo SGGW, Warszawa.

763 O'Keeffe J, Marcinkowski P, Utratna M, Piniewski M, Kardel I, Kundzewicz ZW, Okruszko T. 764 2019. Modelling Climate Change's Impact on the Hydrology of Natura 2000 Wetland Habitats in 765 the Vistula and Odra River Basins in Poland. Water 11:2191.

766 Olde Venterink H, Kardel I, Kotowski W, Peeters W, Wassen MJ. 2009. Long-term effects of 767 drainage and hay-removal on nutrient dynamics and limitation in the Biebrza mires, Poland. 768 Biogeochemistry 93(3):235-252.

769 Palczynski A. 1984. Natural differentiation of plant communities in relation to hydrological 770 conditions of the Biebrza valley. Pol Ecol Stud 10:347-385.

771 Palczynski A, Stepa T. 1991. Biomass production in main plant associations of the Biebrza 772 valley with respect to soil conditions. Pol Ecol Stud 17:53-62.

773 Piniewski M, Mezghani A, Szcześniak M, Kundzewicz ZW. 2017. Regional projections of 774 temperature and precipitation changes: Robustness and uncertainty aspects. Meteorologische 775 Zeitschrift, 26(2):223-234 DOI 10.1127/metz/2017/0813 
776 Piniewski M, Szcześniak M, Kardel I, Berezowski T, Okruszko T, Srinivasan R, Vikhamar 777 Schuler D, Kundzewicz ZW. 2017a. Hydrological modelling of the Vistula and Odra river basins 778 using SWAT. Hydrol. Sci. J. 62:1266-1289.

779 Polakowski M, Broniszewska M, Goławski A. 2014. A comparison of two methods of duck 780 census during the spring migration in a widely flooded river valley. Ornis Polonica 55:279-289.

781 Polakowski M, Kasprzykowski Z, Goławski A. 2018. Influence of temperature on the timing of 782 spring arrival and duration of migration in Arctic goose species at a central European stopover 783 site. Ornis Fennica 95:32-40.

784 Razavi T, Switzman H, Arain A, Coulibaly P. 2016. Regional climate change trends and 785 uncertainty analysis using extreme indices: A case study of Hamilton, Canada. Climate Risk 786 Management 13:43-63.

787 Strupczewski WG, Feluch W. 1998. Investigation of trend in annual peak flow series. Part I. 788 Maximum likelihood estimation. Proceedings of the Second International Conference on Climate 789 and Water 1:241-250.

790 Strupczewski WG, Kaczmarek Z. 1998. Investigation of trend in annual peak flow series. Part II. 791 Weighted Least Squares estimation. Proceedings of the Second International Conference on 792 Climate and Water 1:251-263.

793 Strupczewski WG, Singh VP, Feluch W. 2001. Non-stationary approach to at-site flood794 frequency modelling. Part I. Maximum likelihood estimation. Journal of Hydrology 248:123-142

795 Strupczewski WG, Kaczmarek Z. 2001. Non-stationary approach to at-site flood-frequency 796 modelling. Part II. Weighted least squares estimation. Journal of Hydrology 248:143-151

797 Strupczewski WG, Kochanek K, Feluch W, Bogdanowicz E, Singh VP. 2009. On seasonal 798 approach to nonstationary flood frequency analysis. Physics and Chemistry of the Earth 34:612$799 \quad 618$

800 Strupczewski WG, Kochanek K, Bogdanowicz E, Markiewicz I. 2012. On seasonal approach to 801 flood frequency modelling. Part I: Two-component distribution revisited. Hydrological Processes 802 26(5):705-716 DOI 10.1002/hyp.8179

803 Strupczewski WG, Kochanek K, Bogdanowicz E, Markiewicz I. 2016. Comparison of two 804 nonstationary flood frequency analysis method within the context of the variable regime in the 805 reperesentative Polish Rivers. Acta Geophysica 64(1):206-236.

806 Schneider C, Laizé CLR, Acreman MC, Flörke M.2013. How will climate change modify river 807 flow regimes in Europe? Hydrol. Earth Syst. Sci. 17:325-339.

808 Schneider C, Flörke M, Geerling G, Duel H, Grygoruk M, Okruszko T. 2011. The future of 809 European floodplain wetlands under a changing climate. Journal of Water and Climate 2(2-3): $810 \quad 106-122$. 
811 Swiatek D, Szporak S, Chormański J, Okruszko T. 2008. Hydrodynamic model of the lower 812 Biebrza river flow - a tool for assessing the hydrologic vulnerability of a floodplain to 813 management practices. Ecohydrology \& Hydrobiology, 8(2-4):24-32

814 Thompson JR, Gavin H, Refsgaard A, Sørenson HR, Gowing DJ. 2009. Modelling the 815 hydrological impacts of climate change on UK lowland wet grassland. Wetl. Ecol. Manag. 816 17(5):503-523.

817 Wassen MJ, Peeters WHM Olde Venterink H. 2002. Patterns in vegetation, hydrology and 818 nutrient availability in an undisturbed river floodplain in Poland. Plant Ecology 165:27-43.

819 Wassen MJ, Olde Venterink H. 2006. N and P fluxes in European fens and floodplains. Appl. 820 Veg. Sci. 9:13-222.

821 Wassen MJ, Okruszko T, Kardel I, Chromanski J, Swiatek D, Mioduszewski W, Bleuten W, 822 Qerner EP, Kahloun ME, Betelaan O, Meire P. 2006. Eco-Hydrological Functioning of the 823 Biebrza Wetlands: Lessons for the Conservation and Restoration of Deteriorated Wetlands. [In:] 824 Bobbink R, Beltman B, Verhoeven JTA, Whigham DF (eds.) Wetlands: Functioning, 825 Biodiversity Conservation, and Restoration. Ecological Studies 191:285-310.

826 Witte J, Runhaar J, van Ek R, Van Der Hoek DCJ, BartholomeusRP, Batelaan O, van Bodegom 827 PM, Wassen MJ, van der Zee SEATM. 2012. An ecohydrological sketch map of climate change 828 impacts on water and natural ecosystems for the Netherlands: bridging the gap between science 829 and society. Hydrol Earth Syst Sci 16:3945-3957

830 Zhang H, Huang GH, Wang D, Zhang X. 2011. Uncertainty assessment of climate change 831 impacts on the hydrology of small prairie wetlands, Journal of Hydrology 396(1-2):94-103. 
Figure 1

Case study location 


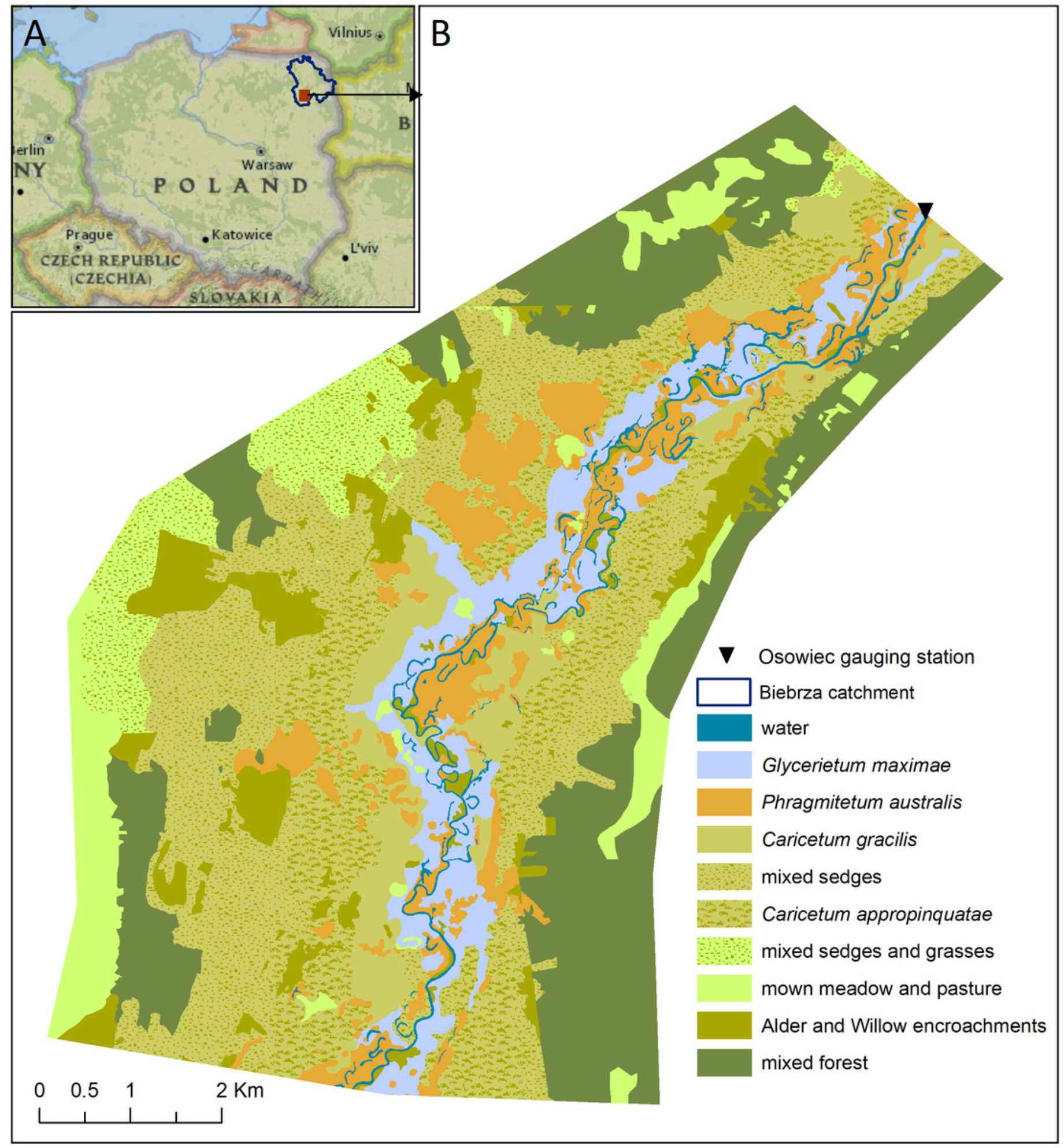


Figure 2

SWAT model simulations vs observed time series in Osowiec gauging station. A - annual precipitation sum in the Biebrza catchment, B - Snow cover thickness in the Biebrza catchment.

A

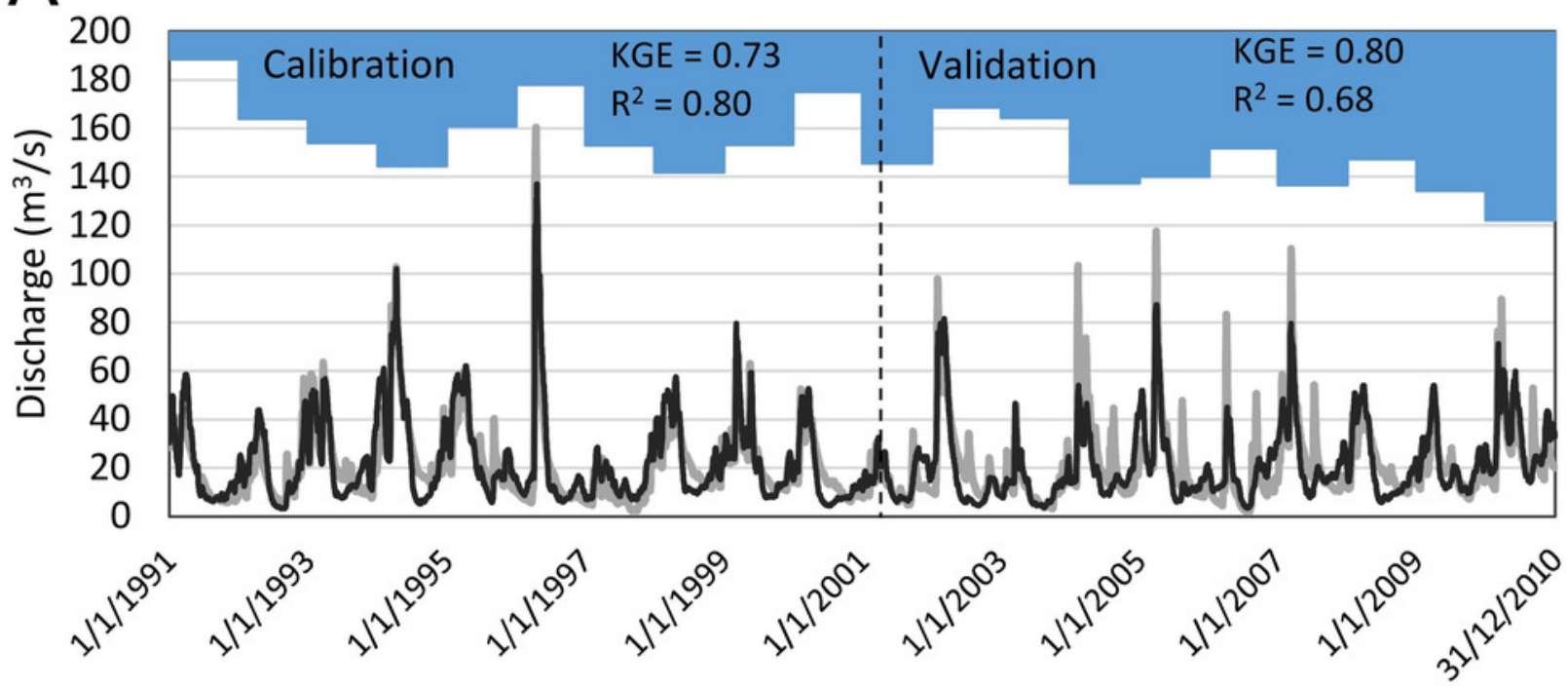

$\mathrm{B}$

precipitation - simulated —observed

400

500

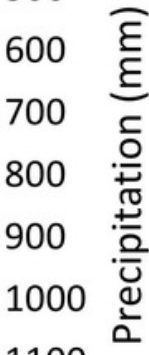

1100

1200

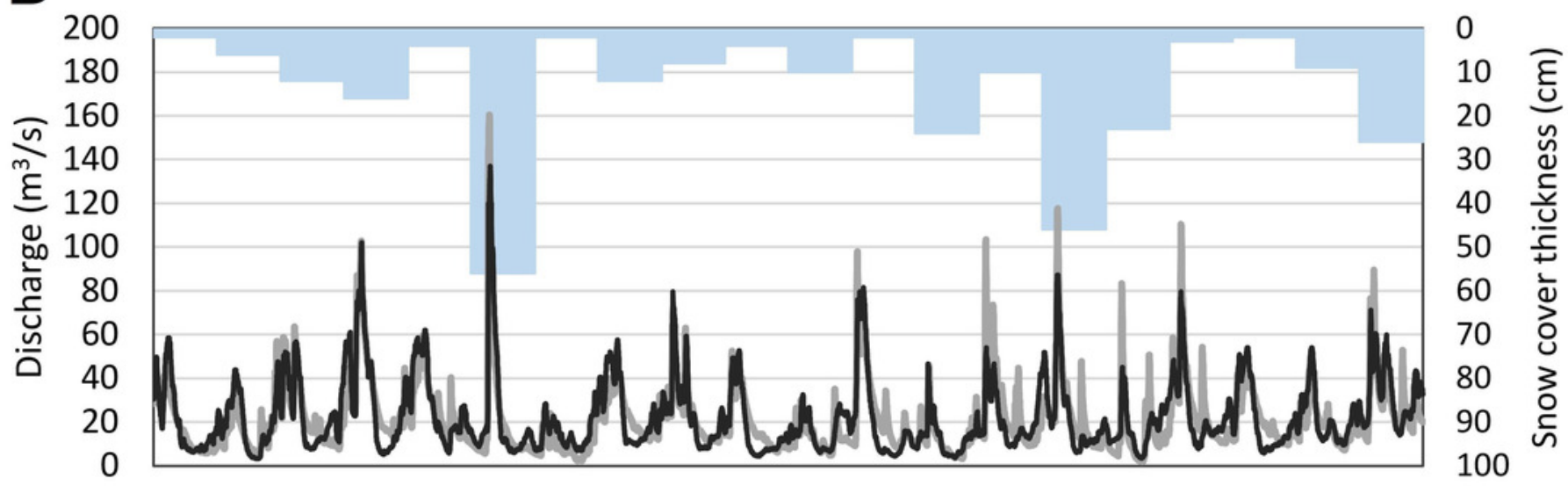


Figure 3

Projected changes in maximum discharge (A), flood duration (B) and volume (C) during winter season based on SWAT model simulations.

Light grey colour stands for actual greenhouse gas concentration, medium grey for RCP4.5 and dark grey for RCP8.5. Boxes denote - 1st to 3rd quartile values, whiskers - non outlier range, circles - outliers, asterisk - extremes, rectangles - mean values and squares - median values.
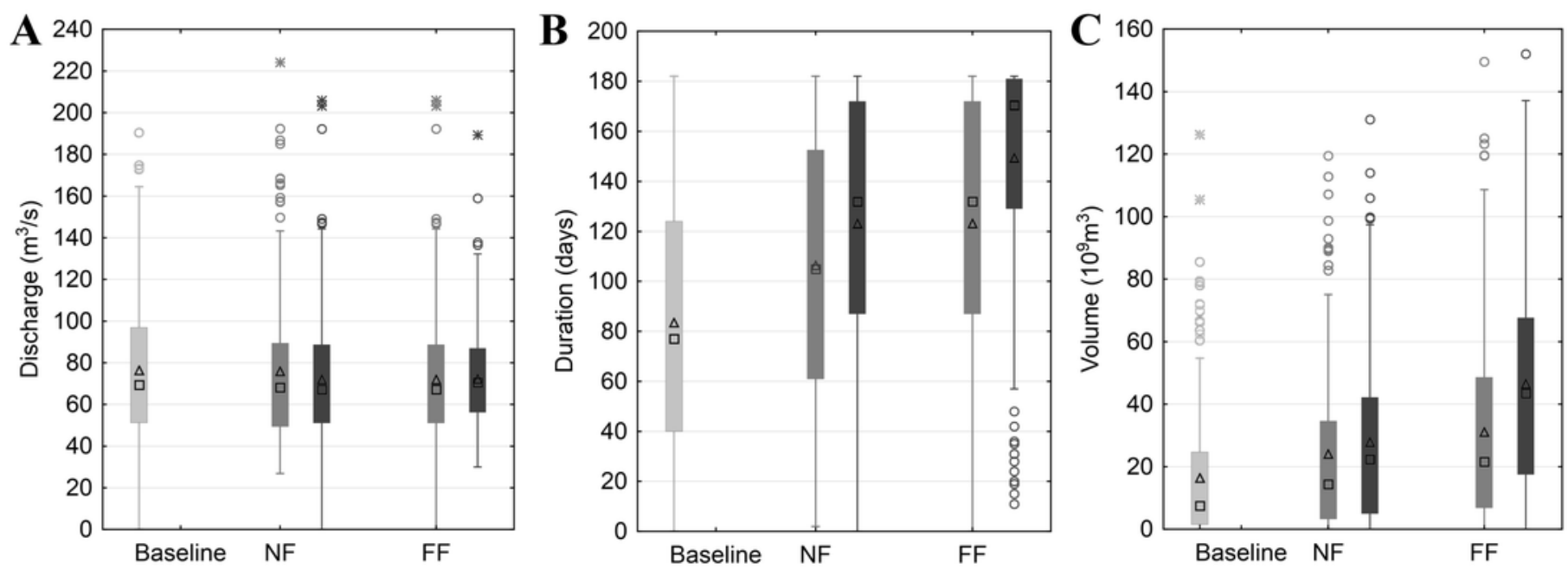
Figure 4

Projected changes in maximum discharge (A), flood duration (B) and volume (C) during summer season based on SWAT model simulations.

Light grey colour stands for actual greenhouse gas concentration, medium grey for RCP4.5 and dark grey for RCP8.5. Boxes denote - 1st to 3rd quartile values, whiskers - non outlier range, circles - outliers, asterisk - extremes, rectangles - mean values and squares - median values.
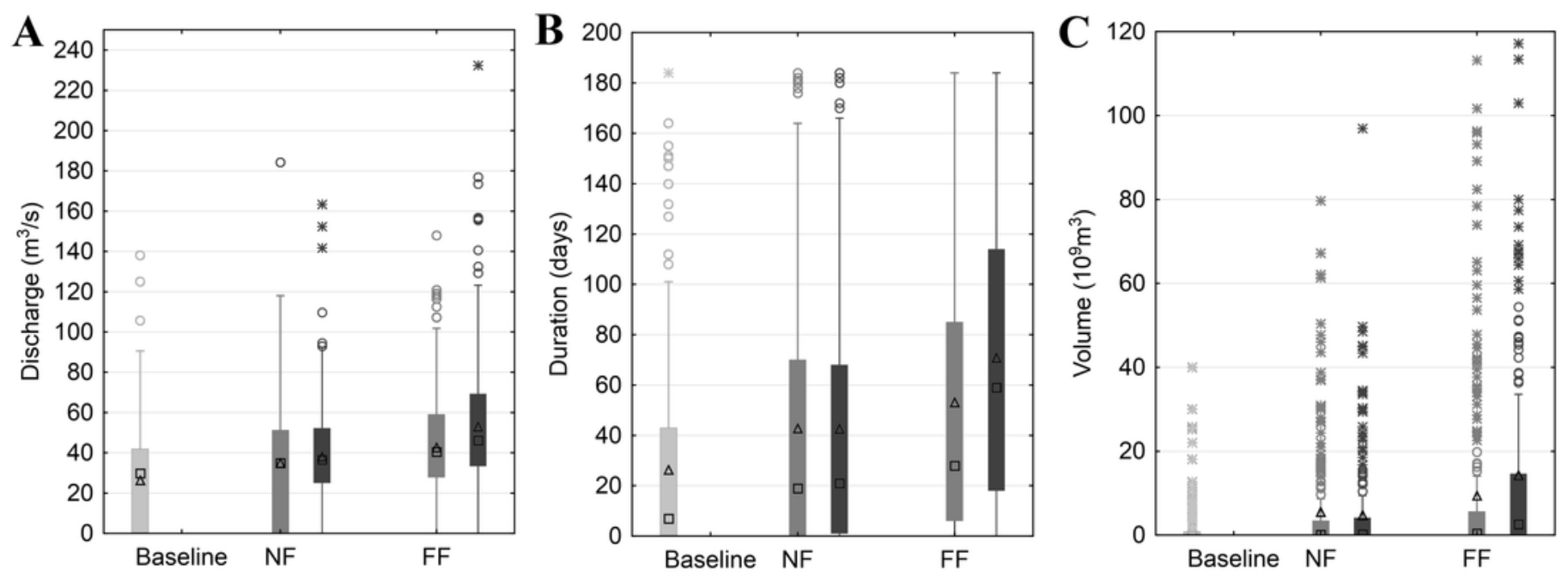
Figure 5

The distribution of the mid-term (14th year of the time series) mean values of:

maximum discharge (A), flood duration (B), flood volume (C) and standard deviation of: maximum discharge (D), flood duration (E), flood volume (F), for RCP4.5 and RCP8.5 scena

The solid line in the middle of the box is the mean value of the results for 9 models. The dominating models for each calculation series are in brackets.

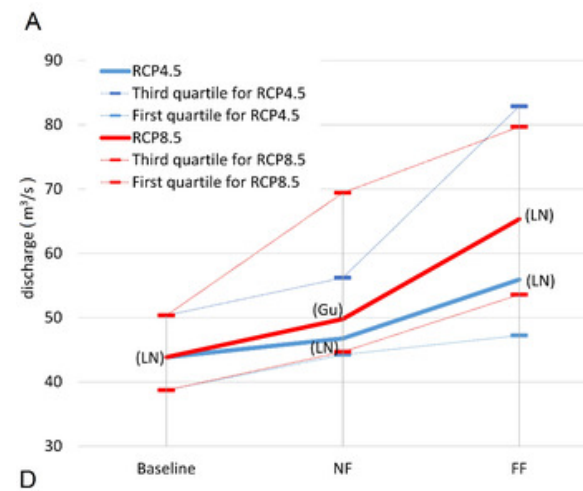

B

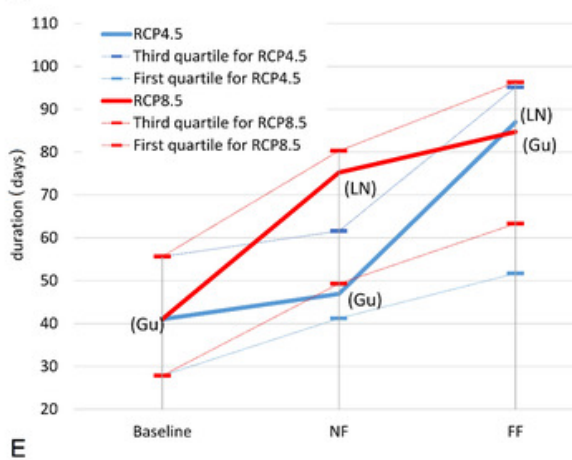

E

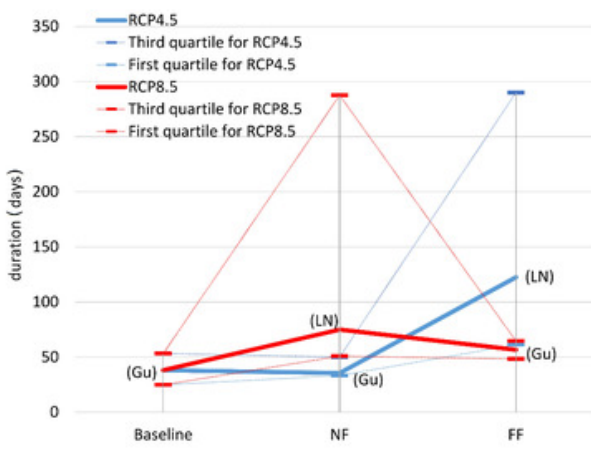

C

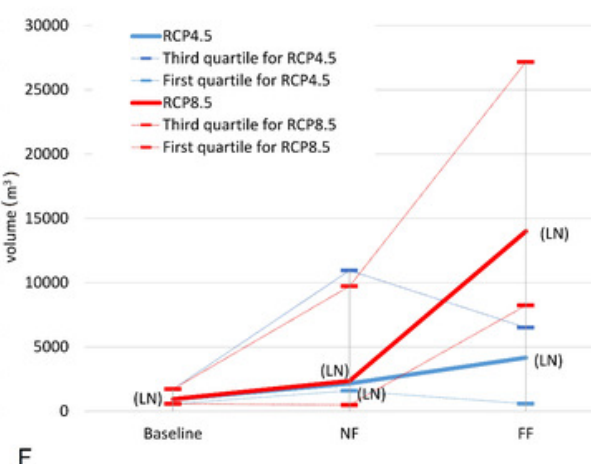

140000

120000

100000

实 80000

- Third quartile for RCP4.5

- First quartile for RCP4.5

- Third quartile for RCP8.5
- First quartile for RCP8.5

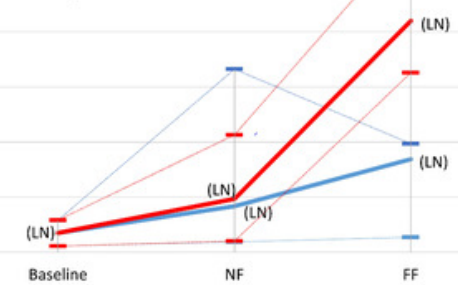


Figure 6

The distribution of the relative values of trends in mean: maximum discharge $(A)$, flood duration (B), flood volume (C) and standard deviation of: maximum discharge (D), flood duration $(E)$, flood volume $(F)$, for the summer season.

The solid line in the middle of the box is the mean value of the results for 9 models. The dominating models for each calculation series are in brackets.

A

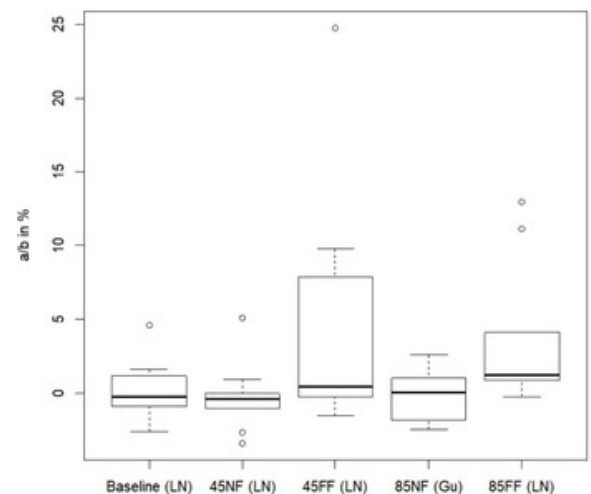

D

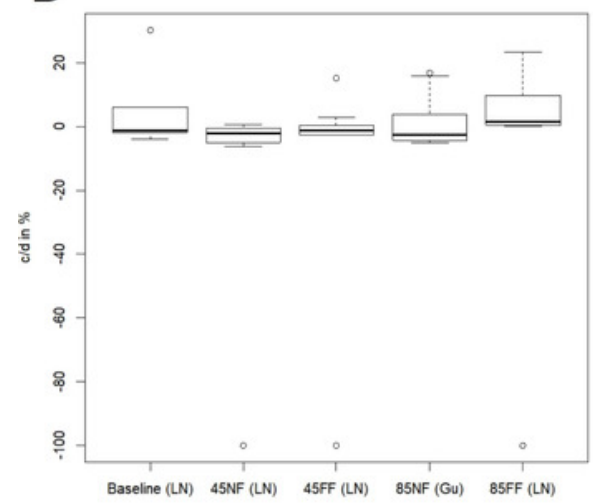

B

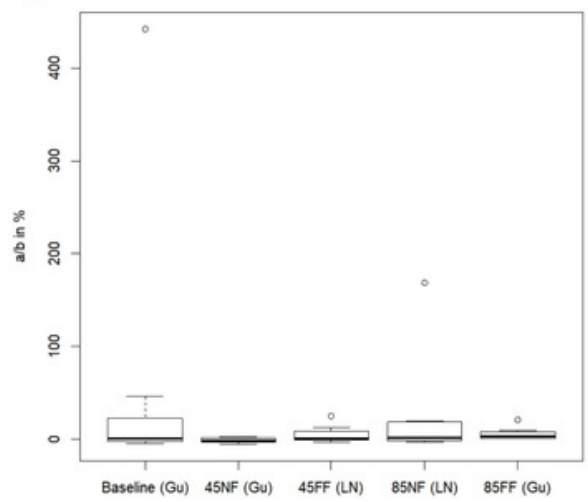

$\mathrm{E}$

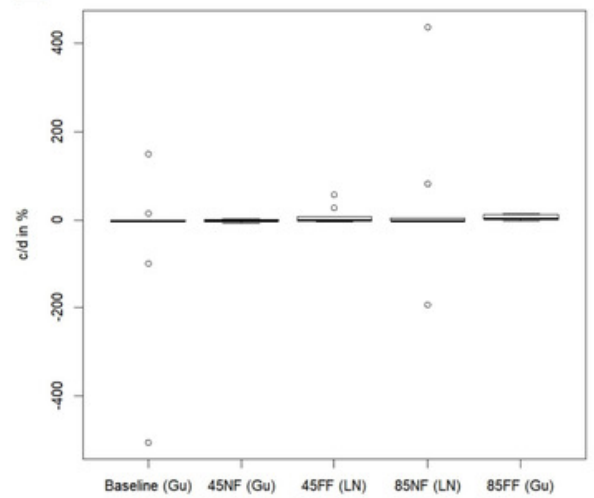

C

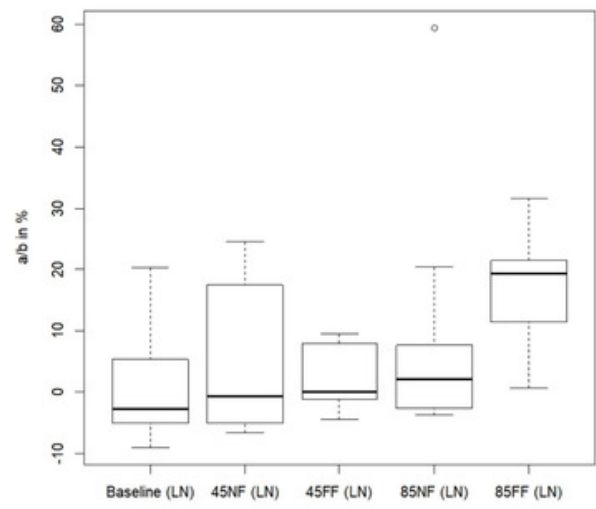

$\mathrm{F}$

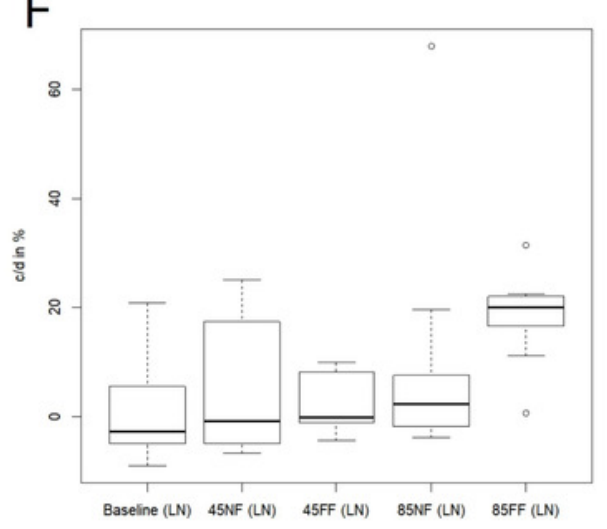


Figure 7

The distribution of the mid-term (14th year of the time series) mean values of:

maximum discharge (A), flood duration (B), flood volume (C) and standard deviation of: maximum discharge (D), flood duration (E), flood volume (F), for RCP4.5 and RCP8.5 scena

The solid line in the middle of the box is the mean value of the results for 9 models. The dominating models for each calculation series are in brackets.
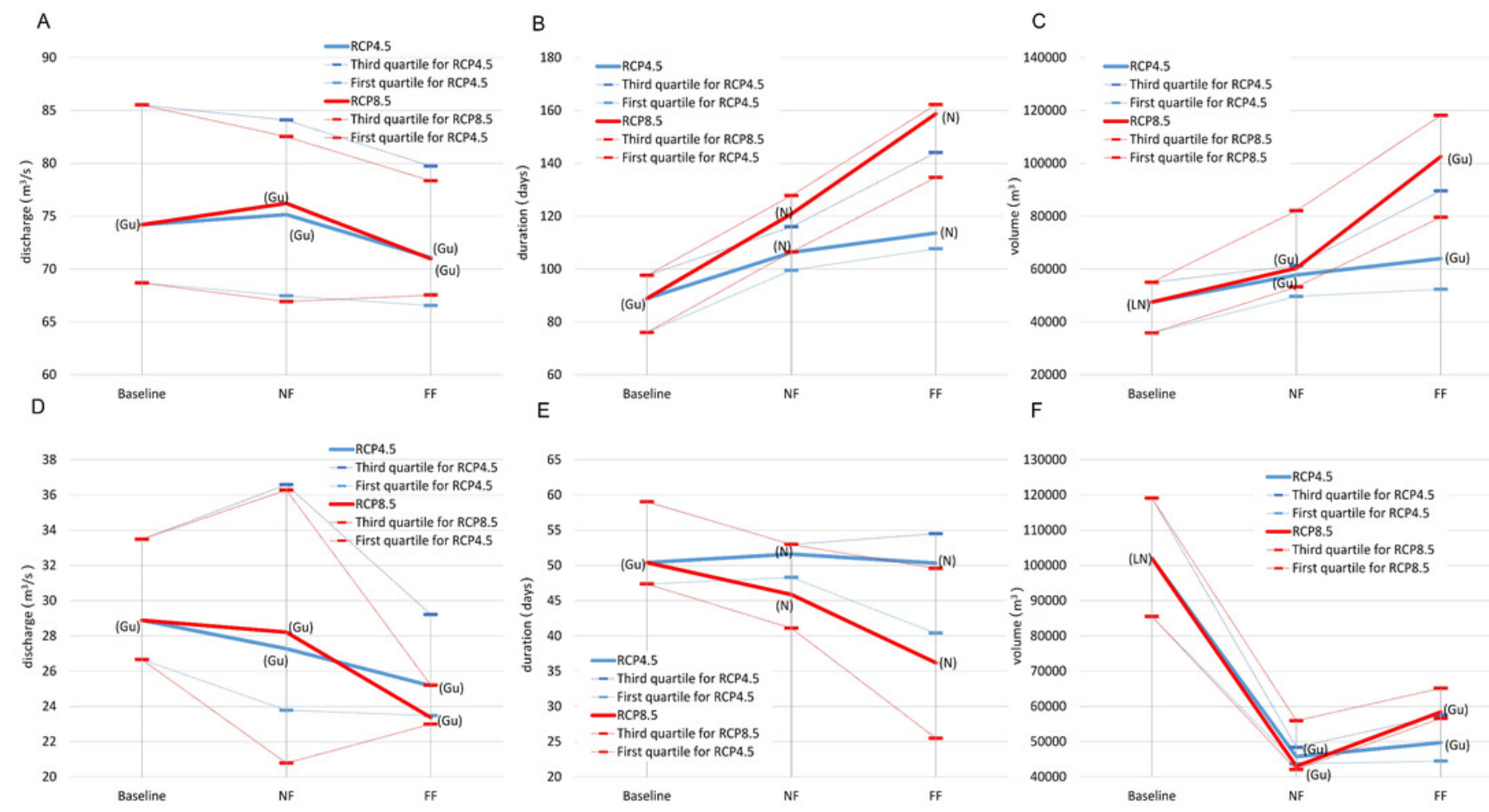
Figure 8

The distribution of the relative values of trends in mean: maximum discharge (A), flood duration (B), flood volume (C) and standard deviation of: maximum discharge (D), flood duration $(E)$, flood volume $(F)$, for the winter season.

The solid line in the middle of the box is the mean value of the results for 9 models. The dominating models for each calculation series are in brackets.

A

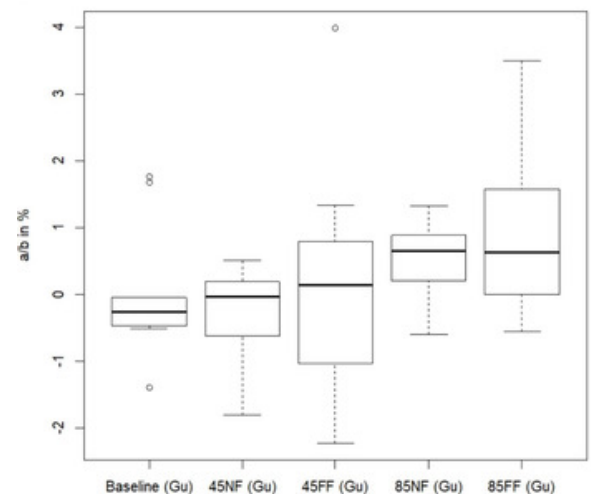

D

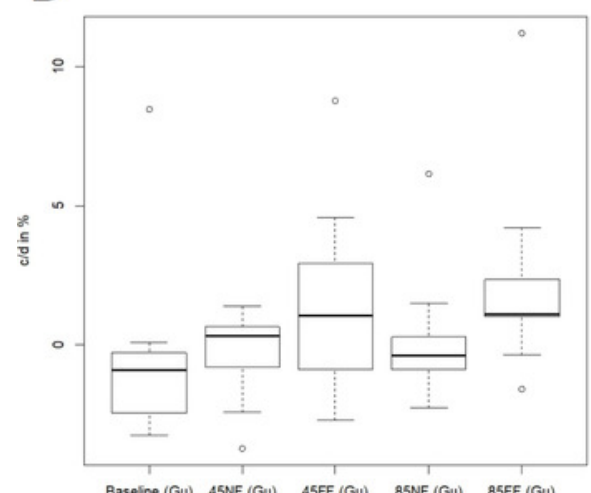

B

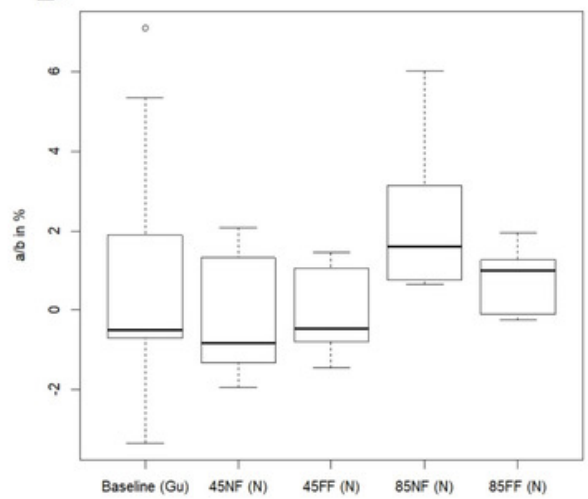

$\mathrm{E}$

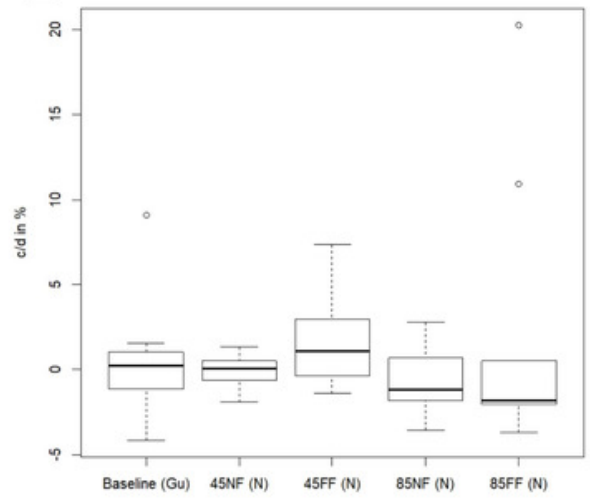

C

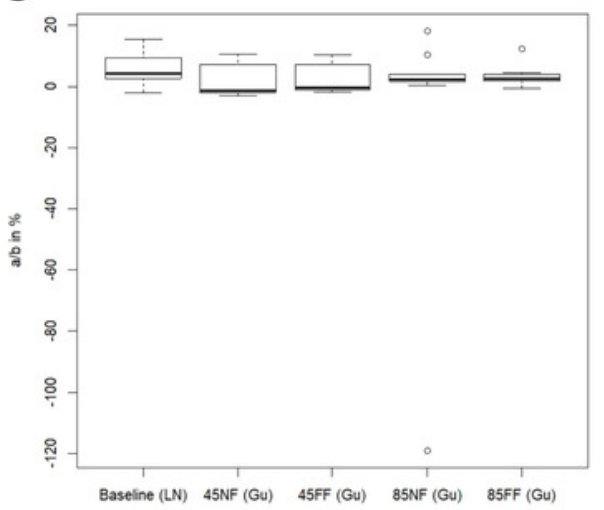

$\mathrm{F}$

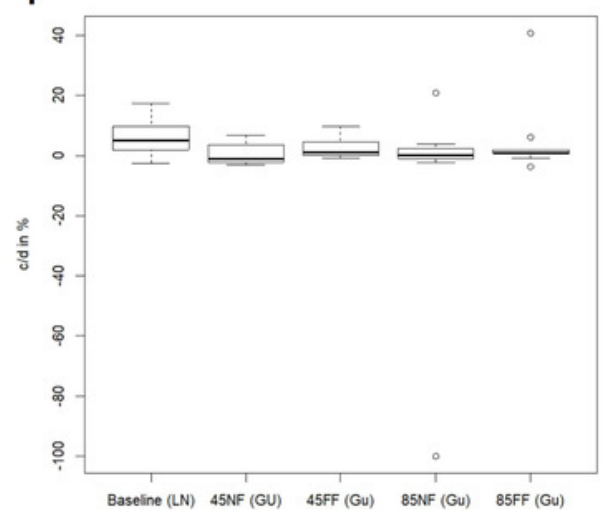


Figure 9

Maximum discharge (Qmax) at Osowiec gauge vs. maximum flood area.

NR - number of raster in DTM.

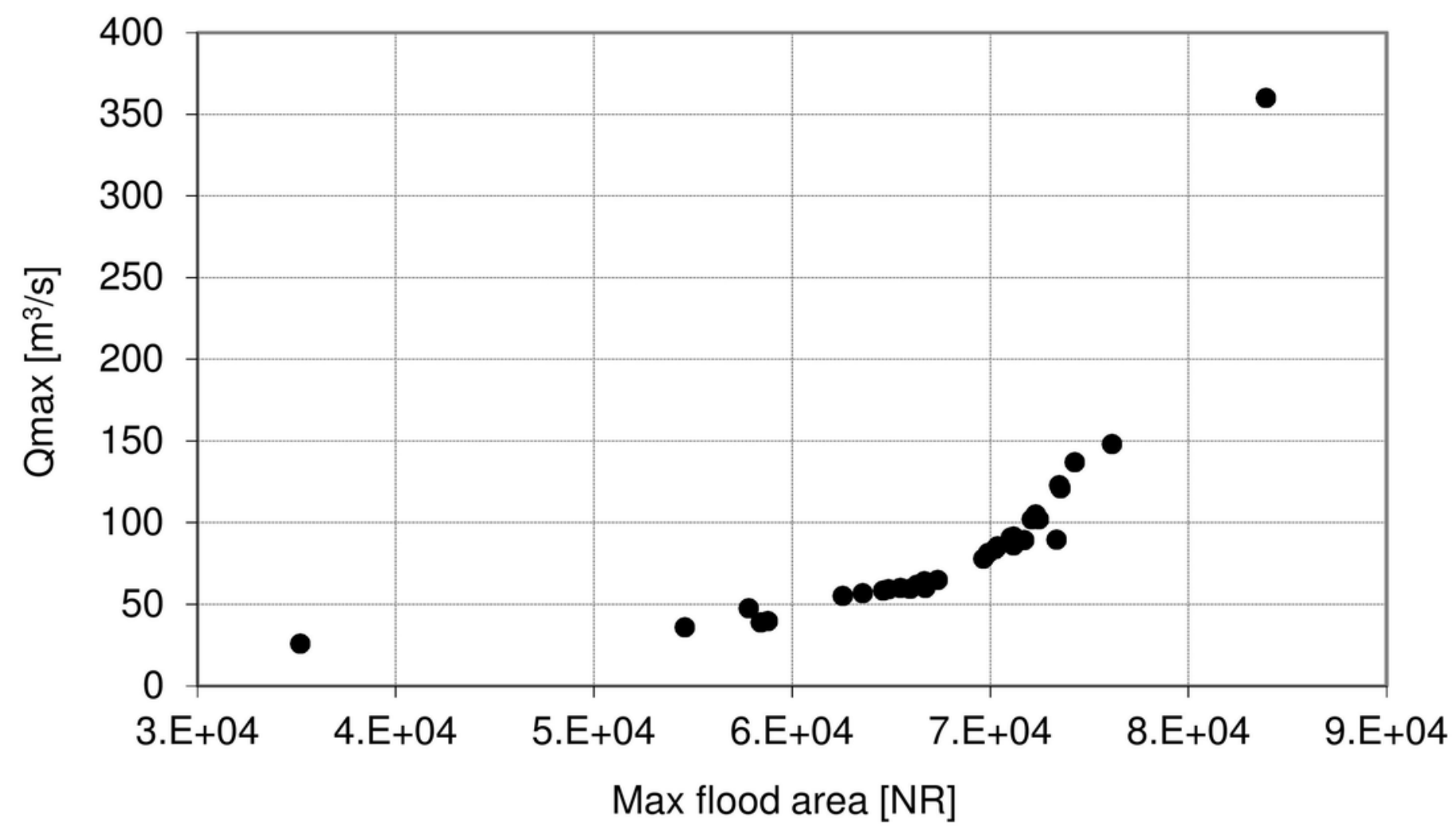


Figure 10

Average time (days) of inundation in Caricetum appropinquatae vs. duration of flood at Osowiec gauge.

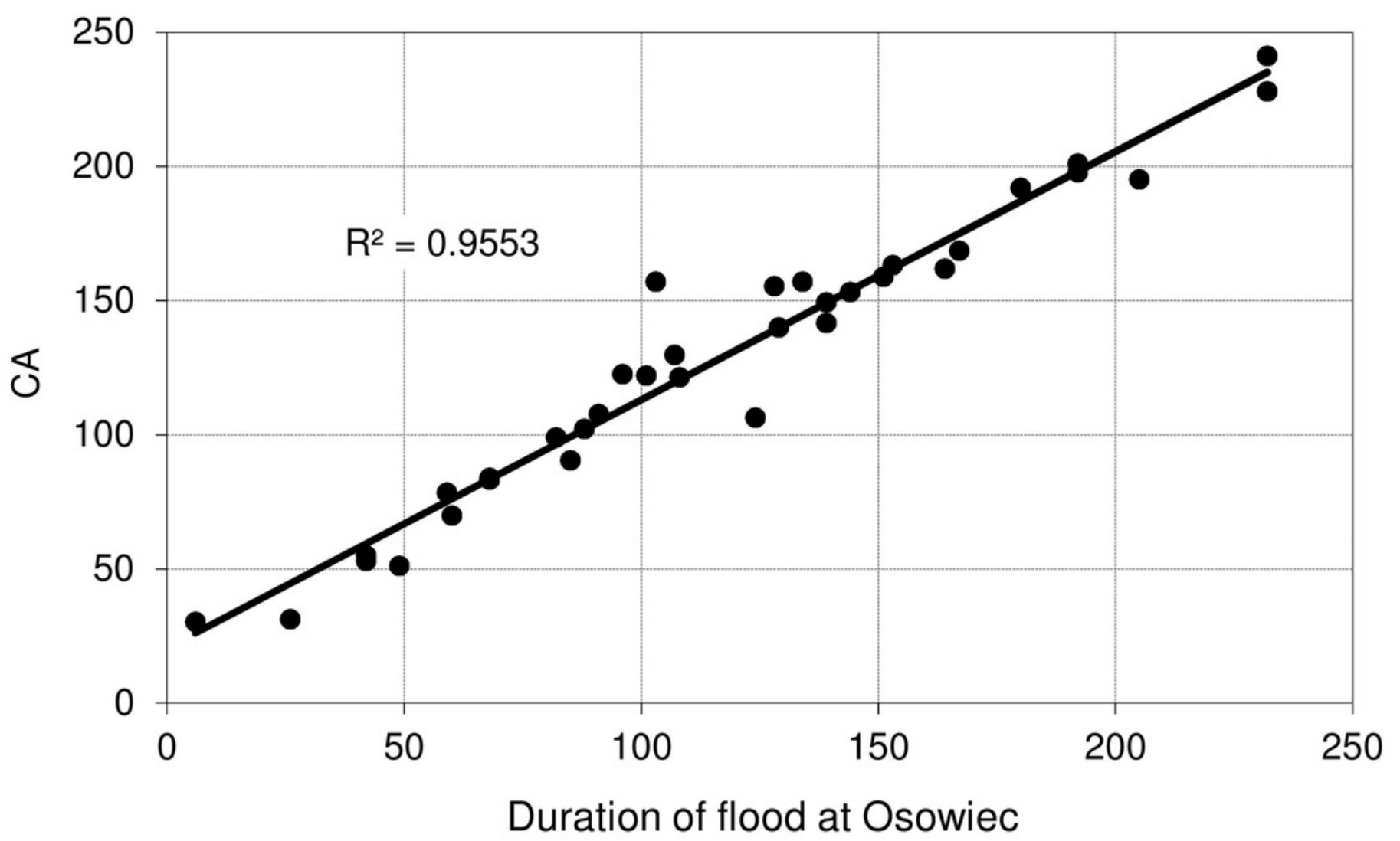


Figure 11

Average time (days) of inundation in Caricetum gracilis vs. duration of flood at Osowiec gauge.

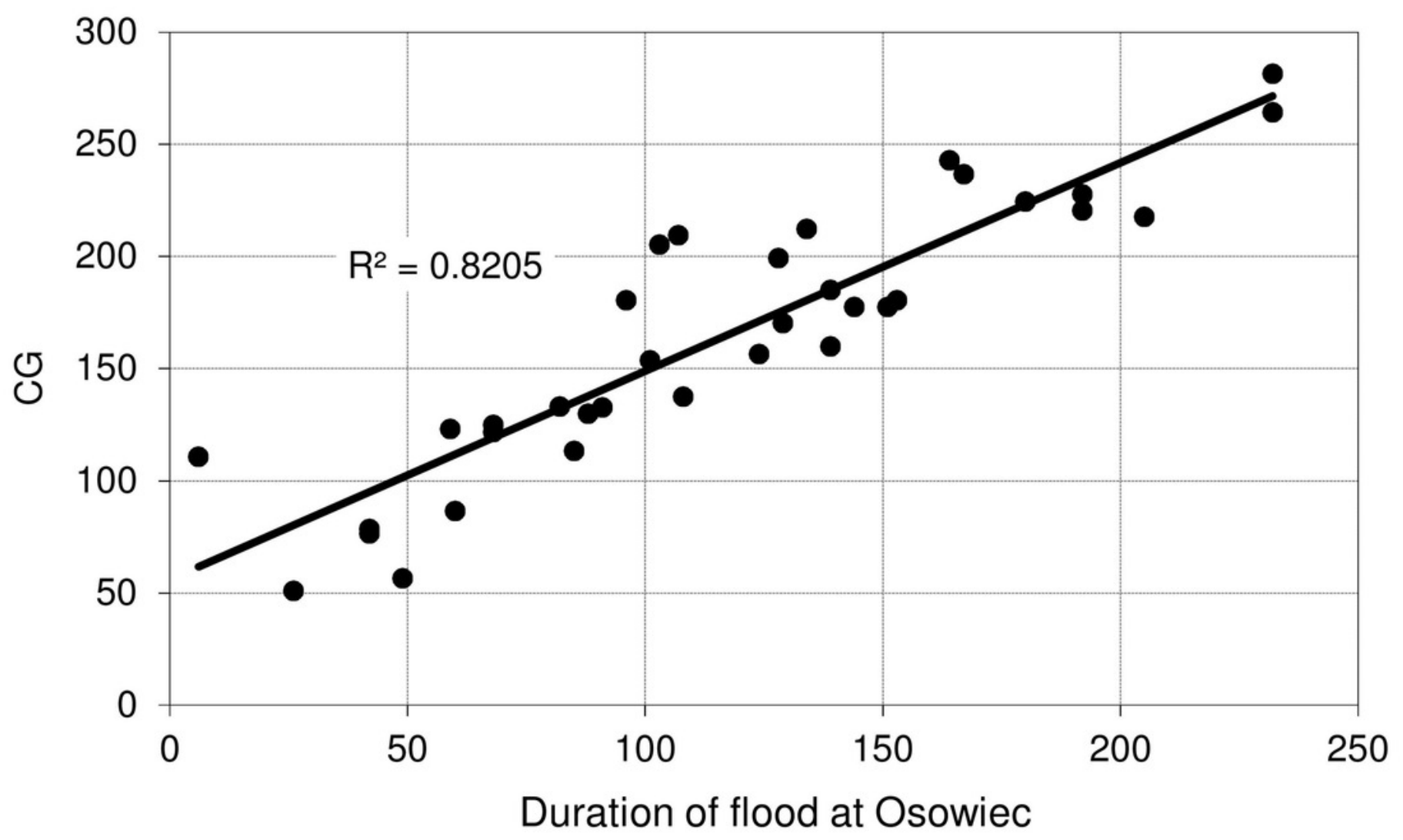


Figure 12

Average time (days) of inundation in Phragmitetum communis vs. duration of flood at Osowiec gauge.

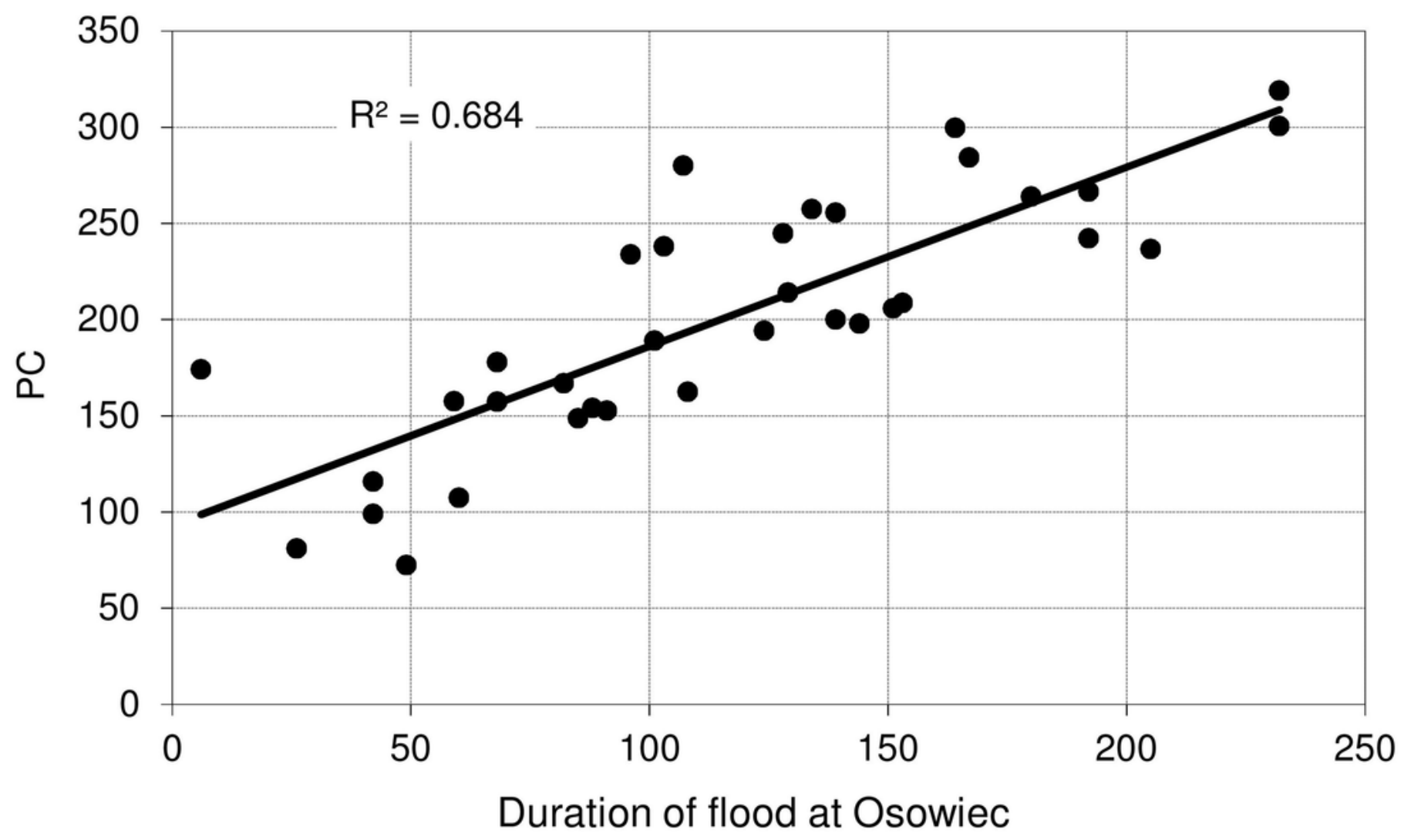


Figure 13

Average time of inundation in Glycerietum maximae vs. duration of flood at Osowiec gauge.

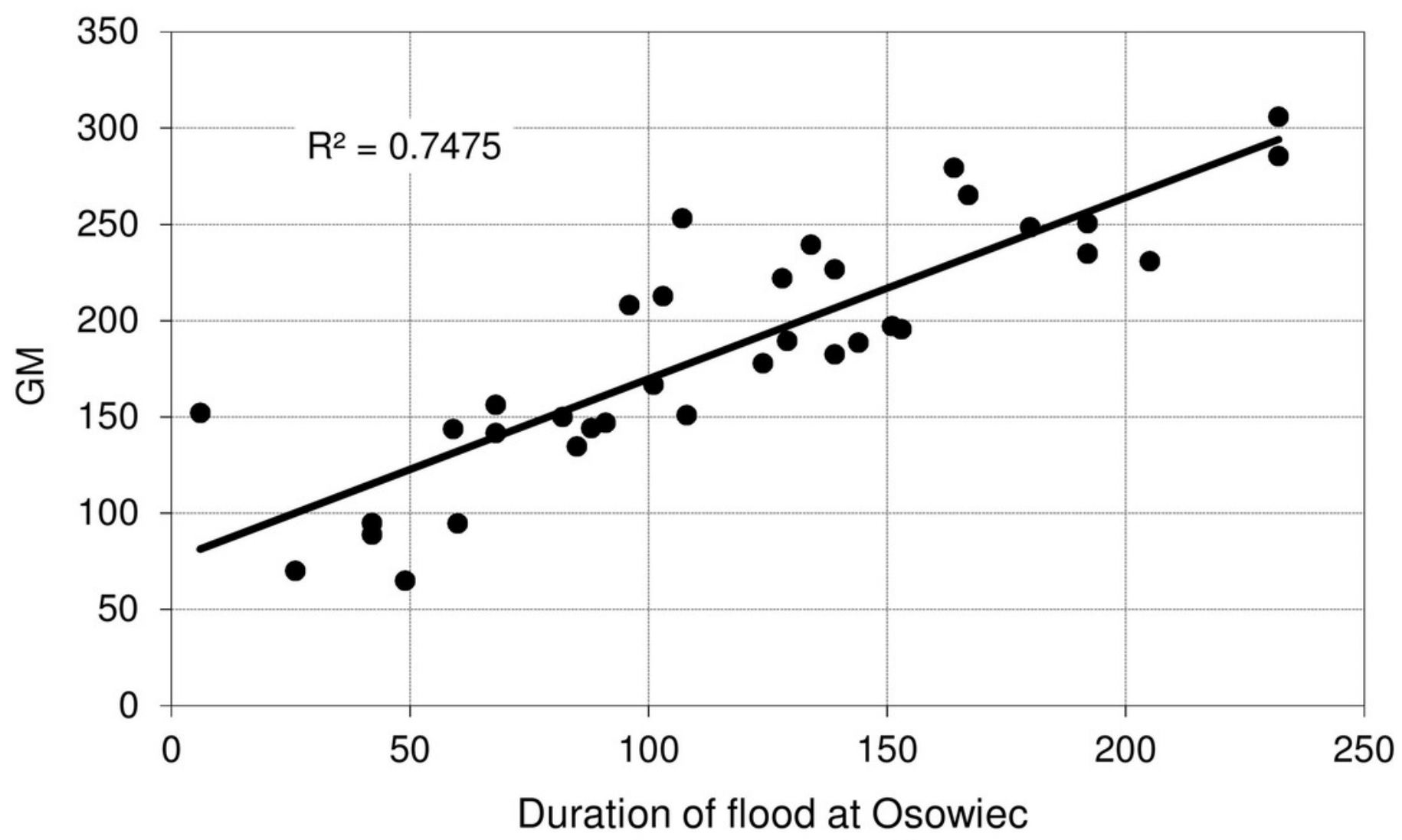

